\title{
De la función punitiva de la responsabilidad aquiliana en Francia: algunas implicancias para la comprensión del derecho de daños chileno*
}

\author{
Cristián Banfi del Rio**
}

\begin{abstract}
RESUMEN
Este artículo analiza la función punitiva genéricamente concebida (esto es, más allá de los "daños punitivos" o indemnización punitiva) de la responsabilidad civil extracontractual y algunas de sus principales manifestaciones en el derecho francés, para luego contrastarlo con el sistema chileno. Se sostiene, desde un punto de vista descriptivo, que el dolo tiene importancia no solo como una razón para aumentar la indemnización del daño moral, sino también como un elemento esencial de la responsabilidad civil derivada del ejercicio de la libertad de competir, del derecho a accionar en juicio y de la libertad de expresión. Desde una perspectiva normativa, se argumenta por el reconocimiento de la influencia causal del dolo, de modo que la responsabilidad debería comprender todos los perjuicios emanados directamente del delito (o de una conducta gravemente negligente), incluyendo los daños que ni siquiera aplicando el más exigente estándar de cuidado babrían podido ser previstos al tiempo de la perpetración del ilícito.
\end{abstract}

Responsabilidad extracontractual - dolo - causalidad - indemnización

\section{On the punitive function of tort liability in France: some implications for the understanding of Chilean tort law}

\begin{abstract}
This article analyses the punitive function generically understood (i.e. beyond punitive damages or punitive compensation for harm) of tort liability and some of its main manifestations in French law, which is then contrasted against the Chilean system. From a descriptive standpoint, it is argued that the intention to harm does matter not only as a reason for increasing liability for pain and suffering but also as an essential ingredient of tort liability flowing from the exercise of the liberty to compete, the right to bring judicial actions and freedom of speech. From a normative perspective, it is contended that the intention to harm should have a causative impact so that liability ought to encompass all damage directly ensued from the delict (or from a grossly negligent conduct), including the losses that not even under the most stringent standard of care could have been foreseen at time the tort was perpetrated.
\end{abstract}

Tort liability - intention to harm - causation - compensation for damages

* Este trabajo se adscribe al Proyecto Fondecyt Regular 1150976 ("Importancia del dolo en la responsabilidad civil extracontractual chilena a la luz de los sistemas francés e inglés"), apoyo que agradezco. Asimismo, aprecio las valiosas observaciones de los árbitros anónimos que revisaron una versión preliminar de este artículo. Por cierto, todos los errores que este contenga son de mi exclusiva responsabilidad.

** Licenciado en Derecho, Pontificia Universidad Católica de Chile; Magíster en Derecho Privado, Universidad de Chile; Magíster y Doctor en Derecho, Universidad de Cambridge. Profesor de Derecho Civil, Universidad de Chile. Correo electrónico: cbanfi@derecho.uchile.cl.

Artículo recibido el 5 de marzo de 2016 y aceptado para su publicación el 1 de marzo de 2017. 


\section{INTRODUCCIÓN}

$\mathrm{E}$ 1 ordenamiento jurídico procura mantener un balance entre la seguridad y la libertad de actuación de las personas, equilibrio que es alterado por el daño y para cuya restauración el sistema se vale de la responsabilidad civil. Si bien la finalidad y función principal de la responsabilidad civil es reparar el daño sufrido por la víctima conforme con la justicia correctiva, este trabajo postula que, en determinadas circunstancias, la responsabilidad también debería atender, y en la práctica persigue, propósitos preventivos y retributivos. Para tal efecto, se revisa la responsabilidad aquiliana en la doctrina y jurisprudencia francesa, la confronta con el sistema nacional y arriba a dos conclusiones: a nivel descriptivo, el dolo no solo determina el incremento de la indemnización del daño moral, sino además es imprescindible para atribuir la responsabilidad por los perjuicios emanados del ejercicio de las libertades de competir, de accionar en juicio y de informar; y, en el plano normativo, la responsabilidad debería abarcar todos los daños derivados directamente del hecho intencional, incluso aquellos imprevisibles a la época de su perpetración.

\section{DERECHO FRANCÉS}

\section{Vigencia de la responsabilidad por culpa}

1.1. Sin dudas, como ocurre en otras jurisdicciones, la responsabilidad estricta ha sido un instrumento de la mayor trascendencia para compensar a las víctimas de actividades riesgosas en Francia. Sin embargo, la culpa ha sido, es y sigue siendo el principal fundamento ético, normativo y racional de la responsabilidad civil ${ }^{1}$. Un célebre jurista galo, quizá exagerando, afirmó que la responsabilidad sin culpa es una ficción ${ }^{2}$. Filosóficamente, la culpa es un puente entre la libertad y la responsabilidad ${ }^{3}$; económicamente, la responsabilidad por culpa incentiva el ejercicio de la libertad de actuación. Por el contrario, la seguridad absoluta contra el riesgo de ser dañado conduciría a la inercia, si no a la ruina económica y social. Una sociedad financieramente saludable propende a que los individuos actúen con el menor número de reglas y controles, mientras que una cautela excesiva puede transformarse en la peor de las imprudencias. Por eso, el sistema jurídico debe procurar un balance entre dos fines a menudo contradictorios:

${ }^{1}$ Radé, D. "L'impossible divorce de la faute et de la responsabilité civile", en Recueil Dalloz Sirey (“D”.), Paris, 1998, Chronique, pp. 301-305; Conte, P., “Responsabilité du fait personnel”, en Savaux, É. (ed.), Dalloz répertoire de droit civil. Dalloz encyclopédie juridique, Paris, Dalloz, 2009, T. X, § 5; Le Tourneau, P., "Responsabilité (en général)", en Savaux (nota 1), §§ 107 y 110.

2 "Parler de responsabilité sans faute, de faute sans acte illicite...c'est comme parler d'un homme sans tête, d'une automobile sans moteur, d'un syllogisme sans prémisses": Esmein, P., "Le fondement de la responsabilité contractuelle", en Revue Trimestrielle de Droit Civil ("RTD. Civ".), 1933, p. 627.

${ }^{3}$ Conseil constitutionnel, 22.7.2005, No 2005-522, Jurisclasseur périodique (Semaine Juridique) édition génerale (“JCP”), 2006, I. 111, obs. Stoffel-Munck; Le Tourneau (nota 1), § 114. 
la necesidad de proteger los derechos de las potenciales víctimas y la libertad de actuación de los posibles autores de los daños ${ }^{4}$.

1.2. La responsabilidad por culpa ha sido expandida para proteger a los agentes comerciales, como expresión del liberalismo jurídico-económico. Ella opera como un filtro moralizador de las relaciones entre quienes confluyen al mercado guiados por intereses divergentes ${ }^{5}$. Entre las áreas más relevantes de aplicación de la responsabilidad por culpa destacan aquellas conformadas por los actos de competencia desleal y las conductas anticompetitivas $^{6}$. La responsabilidad por culpa, particularmente mediante las acciones de competencia desleal basadas en los arts. 1382 y 1383 del Code, cumplen un claro rol normativo de la actividad mercantil. De ahí que la jurisprudencia defina los usos comerciales y las reglas de conducta de modo coherente con los principios de lealtad e igualdad que subyacen a la competencia. De esta manera, la responsabilidad por culpa es un medio adecuado para sopesar los principios de lealtad e igualdad que vinculan a los rivales. En estos casos es evidente que la responsabilidad civil no solo sirve para indemnizar sino también para prevenir y castigar los comportamientos antisociales ${ }^{7}$.

\section{Noción y relevancia del dolo y de la culpa grave}

2.1. Mientras el derecho penal enfatiza la culpabilidad del hechor, la culpa civil generalmente no supone un reproche personal al agente. Con todo, el dolo civil tiene cierta conexión con el dolo penal: aquel es apreciado en concreto, según las características subjetivas del autor del daño ${ }^{8}$. Esta relación entre pena y delito civil asimismo obedece al efecto de cosa juzgada de las sentencias condenatorias penales en los juicios civiles. Ahora bien, el análisis del delito civil no exige al juez indagar acerca de los motivos detrás de la conducta del demandado sino solo establecer, mediante su razonamiento y presunciones, si este actuó o no con intención de dañar ${ }^{9}$. Además, el principio de legalidad imperante en derecho penal hace que la culpa de este ámbito sea más específica que la culpa civil, de suerte que puede negarse la existencia de una y afirmarse la de la otra $^{10}$. Así, la ausencia de injuria penal no excluye la intención constitutiva del acto de denigración que genera responsabilidad civil ${ }^{11}$.

\footnotetext{
${ }^{4}$ Le Tourneau (nota 1$), \S 118$.

${ }^{5}$ Le Tourneau (nota 1), $\S 120$ y 137.

${ }^{6}$ Ballot-Léna, A., La responsabilité civile en droit des affaires, Paris, LGDL, 2008; Chagny, M., Droit de la concurrence et droit commun des obligations, Paris, Dalloz, 2004.

${ }^{7}$ Pollaud-Dulian, F., "De quelques avatars de l'action en responsabilité civile dans le droit des affaires", en Revue Trimestrielle de Droit Commercial (“RTD. Com”.), 1997, pp. 348-381, en especial pp. 351-353.

${ }^{8}$ Civ. (2) 19.10.1988, Bulletin des arrêts des chambres civiles de la Cour de cassation (Bull. civ.), II, No 200.

${ }^{9}$ Conte (nota 1$), \S \S 15,18-20$ y 62.

${ }^{10}$ Civ. (2) 21.11.1956, D., 1957, p. 52; Civ. (2) 13.2.1991, Bull. civ., II, No 51.

${ }^{11}$ Conte (nota 1$), \S 64$.
} 
2.2. El dolo civil comprende tanto la intención de dañar como la previsión -con una alta probabilidad ${ }^{12}$ - de que el acto respectivo dañará a un tercero ${ }^{13}$. El límite entre dolo y culpa grave es frágil. Primero, ambas categorías importan una transgresión ostensible del principio de buena fe consagrado en el art. 1134 inc. $3^{\circ}$ del Code ${ }^{14}$. Segundo, la negligencia grave y la culpa inexcusable son próximas al dolo eventual, concepto asociado tradicionalmente al derecho penal. La culpa lata es asimilada al dolo, pues una imprudencia extrema implica, o al menos permite colegir, la intención de perjudicar ${ }^{15}$. Típicamente, la jurisprudencia califica como sumamente descuidado el incumplimiento que revela la incapacidad del deudor para honrar sus obligaciones elementales o esenciales ${ }^{16}$; en cambio, no lo son el mero retardo del transportista en entregar la mercadería al destinatario ${ }^{17}$, el incumplimiento de la prestación que el deudor debió ejecutar fácilmente pues contaba con todos los medios necesarios para lograrlo ${ }^{18}$ y la reiteración de errores e inadvertencias de lo que el deudor sabía o debía saber ${ }^{19}$. De ahí que la culpa lata también es equiparada al dolo extracontractual ${ }^{20}$.

2.3. La responsabilidad contractual en principio está limitada a los daños que las partes pudieron prever al tiempo de celebrar el contrato, por así disponerlo el art. 1150 del Code, regla que se funda en la voluntad presunta de aquellas ${ }^{21}$. Esta limitación obedece también al nexo causal que existe entre el contrato y el derecho a la indemnización del contratante diligente, ya que dicho precepto alude al contrato mientras que el art. 1151, que trata del dolo, hace referencia a la inejecución contractual. Esto reforzaría la idea de que la indemnización de perjuicios generalmente queda cubierta por el acuerdo entre

${ }^{12}$ El dolo supone la asunción por el sujeto de la máxima probabilidad del resultado, en cuanto que es deseado por él. En la culpa lataldolo eventual, el autor no desea el daño, pero asume que existe una elevada probabilidad de que se produzca. En la culpa levísima, la previsibilidad del resultado es prácticamente inexistente y totalmente nula en el comportamiento diligente. Por esto, el juicio de previsibilidad no solo determina la imputabilidad subjetiva, sino también la cuantía del daño resarcible: Reglero, F., Tratado de responsabilidad civil, Navarra, Thomson Reuters, 2014, $5^{\text {a }}$ ed., T. I., p. 304.

13 Civ. (1) 4.2.1969, D., 1969, p. 601, n. Mazeaud.

${ }^{14}$ Jambu-Merlin, R., "Dol et faute lourde", en D., Paris, 1955, Chronique, p. 89; Nguyen, D., "Contribution a l'étude de la faute contractuelle: le faute dolosive et sa place actuelle dans la gamme des fautes", en RTD. Civ., 1973, pp. 496-521.

${ }^{15}$ Viney, G., en D., 1975, Chronique, p. 263. En contra, se dice que la presunción general de buena fe impide asimilar la culpa grave a la malicia: Viney, G. y Jourdain, P., Traité de droit civil. Les conditions de la responsabilité, Paris, LGDJ, 2006, $4^{\mathrm{e}}$ éd., pp. 629 y 673-674.

${ }^{16}$ Civ. (1) 1.3.1983, Gaz. Pal, 1984, 1, panor., p. 58, obs. Chabas; Civ. (1) 30.11.2004, Bull. civ., I, No 295; Com. 21.2.2006, D., 2006, AJ, p. 717, obs. Chevrier.

${ }^{17}$ Civ. (2) 11.12 .1952$, D., 1953, p. 317, n. Savatier.

${ }^{18}$ Com. 11.5.1976, D., p. 76, Sommaires commentés (“somm”.) 64; Com. 30.6.2004, Bull. civ., IV, No 144.

${ }^{19}$ Civ. (1) 5.2.1957, D., 1957, p. 232; Com. 3.4.2001, Bull. civ., IV, No 70.

${ }^{20}$ Civ. 8.10.1975, D., 1975, Informations rapides (“IR”), p. 258; Viney y Jourdain (nota 15), pp. 623, 659 y ss.

${ }^{21}$ Mazeaud, H. y Mazeaud, L., Traité théorique et pratique de la responsabilité civile délictuelle et contractuelle, Paris, Sirey, 1949, $4^{\mathrm{e}}$ éd., N 2375; Le Tourneau (nota 1), §§ 87-88. 
las partes, salvo en el caso del incumplimiento doloso ${ }^{22}$. En este sentido, un sector de la doctrina sostiene que la previsibilidad y la causalidad son criterios diferentes e incompatibles de determinación del daño, cada uno de estos debe ser aplicado exclusivamente en sus respectivos dominios. Así, la fuente de la indemnización de los daños previsibles es el contrato (art. 1150), mientras que la fuente de la indemnización de los daños imprevisibles (art. 1151) es el delito civil -en la especie, el incumplimiento contractual doloso- bajo la norma de causalidad ${ }^{23}$. Para otros autores, el art. 1150 presupone una relación de causalidad entre el contrato y los daños previsibles, nexo que es interrumpido por el dolo: los daños resarcibles (previsibles e imprevisibles) emanan directamente del incumplimiento doloso (art. 1151) y no del contrato.

2.4. Luego, la responsabilidad por incumplimientos dolosos -y también gravemente negligentes- se basa íntegramente en la causalidad y no en la previsibilidad: el dolo o la culpa lata es la causa directa e independiente de los perjuicios indemnizables, no las previsiones contractuales. El dolo traslada a las partes al terreno delictual. Por eso, mediante la indemnización no se persigue colocar al contratante diligente en la situación en que se hallaría si el deudor hubiese cumplido sus obligaciones sino que en aquella en que se encontraba antes de padecer el incumplimiento ${ }^{24}$. Este argumento tiene asidero en la historia de la ley: los codificadores admitieron que la infracción contractual dolosa engendra una obligación nueva y diferente de las que emanan del contrato, a saber, la de resarcir todos los daños -incluso imprevisibles- que ese hecho irroga al contratante cumplidor $^{25}$.

2.5. La jurisprudencia no confina el dolo a la intención de dañar al acreedor sino que lo extiende al incumplimiento consciente o deliberado, aunque falte dicha intención, porque este igualmente vulnera el principio de la buena $\mathrm{fe}^{26}$. Esta concepción es congruente con la asimilación de la culpa grave que es reconocida por la jurisprudencia pese a no estar consagrada en la ley ${ }^{27}$. En efecto, si bien la culpa lata difiere claramente de la intención de dañar como fin per se, la desconsideración absoluta hacia los demás es cercana al incumplimiento consciente. Por eso, la culpa grave deviene en una presunción de dolo con lo que se pretende impedir que el autor del daño que actuó con extrema indiferencia eluda su responsabilidad bajo el pretexto de que no quiso lesionar

${ }^{22}$ Quézel-Ambrunaz, C., Essai sur la causalité en droit de la responsabilité civile, Paris, Dalloz, 2010, pp. 465-468.

${ }^{23}$ Souleau, I., La prévisibilité du dommage contractuel, défense et illustration de l'article 1150 du Code Civil, Paris, Université de Droit, d'Économie et Sciences Sociales, 1979, thèse, No 218; Coëffard, P., Garantie des vices cachés et responsabilité contractuelle de droit commun, Paris, LGDJ, 2005, Nos 133 y 154.

${ }^{24}$ Quézel-Ambrunaz (nota 22), pp. 471-474.

${ }^{25}$ Bigot de Préameneu, F.J.J., "Présentation au corps législatif et exposé de motifs", en Fenet, P-A., Recueil complet des travaux préparatories du Code civil, Paris, 1827, t. 13, p. 233. "Es del mismo dolo de donde procede la obligación de reparar las consecuencias": Demolombe, C., Traité des contrats ou des obligations conventionelles en général. Cours de Code Napoléon, Paris, Durand-Hachette, 1868, vol. XXIV, T. I, No 598.

${ }^{26}$ Civ. (1) 4.2.1969, D., 1969, p. 601, n. Mazeaud: quien incumple un contrato no busca dañar a la otra parte sino satisfacer un interés propio incompatible con el de aquella.

${ }^{27}$ Com. 25.3.1963, D., 1964, p. 17, n. Rodière. 
a la víctima ${ }^{28}$. Esta noción amplia del dolo es sensata, pues quien comete voluntariamente un hecho cuya consecuencia ineludible -o casi cierta- es el daño a un tercero, probablemente quiere causar este resultado, es decir, no solo actúa con la intención de crear un riesgo sino también con la de que este se materialice en un daño, o al menos acepta su consumación ${ }^{29}$.

2.6. Una de las razones que se aduce para agravar la responsabilidad contractual es que el deudor doloso o sumamente imprudente se asemeja a quien perpetra un delito civil, pues se comporta como si jamás hubiese contratado. Para quienes niegan la existencia de la responsabilidad contractual y alegan que la indemnización de perjuicios es el cumplimiento por equivalencia de la misma obligación que el deudor asumió voluntariamente, el dolo es el único elemento que da lugar a una nueva obligación que el contrato no contenía: la de responder de los daños imprevisibles ${ }^{30}$. Análogamente, se argumenta que quien incumple dolosamente sus obligaciones contractuales no puede pretender que su conducta sea regida por el derecho de contratos, ya que este se funda en la confianza que aquel comportamiento vulnera abiertamente ${ }^{31}$. Luego, el incumplimiento contractual deliberado, o gravemente negligente, constituye un delito civil. Prueba de esto es que la prohibición general de la opción o cúmulo ${ }^{32}$ no es aplicada a los incumplimientos contractuales dolosos o gravemente culpables: el contratante afectado puede demandar al infractor conforme al estatuto aquiliano ${ }^{33}$. Es decir, se prescinde de la prohibición aludida pues el incumplimiento deliberado envuelve una "culpa exterior al contrato" 34 , esto es, dolo ${ }^{35}$.

\section{El dolo y la culpa lata hacen una diferencia en el ámbito extracontractual}

3.1. En la jurisprudencia francesa la distinción entre delitos y cuasidelitos suele pasar inadvertida, pues impera el principio de la reparación integral. La responsabilidad civil es un instrumento esencialmente resarcitorio que atiende a la magnitud del daño sufrido

${ }^{28}$ Mazeaud, H., Mazeaud, L., Mazeaud, J. y Chabas, F., Leçons de droit civil, Paris, Montchrestien, 1998, $9^{\mathrm{e}}$ éd., pp. 452-456.

${ }^{29}$ Conte (nota 1$), \$ \$ 70-74$.

${ }^{30}$ Le Tourneau, P., "La verdeur de la faute dans la responsabilité civile (ou de la relativité de son déclin)”, en RTD. Civ., 1998, pp. 505-518; Galand-Carval, S., "Fault under French law”, en Widmer, P. (ed.), Unification of tort law: fault, European Centre of Tort and Insurance Law, The Hague, Kluwer, 2005, vol. 10, pp. 95-96.

${ }^{31}$ Leturmy, L., "La responsabilité délictuelle du contractant", en RTD. Civ., 1998, pp. 839, 867 y ss.

${ }^{32}$ Civ. 21.7.1890, Recueil périodique Dalloz ("DP”), 1891, 1, p. 380; Com. 9.7.2002, RTD. Com., 2003, p. 363, obs. Bouloc; Serra, Y., “Concurrence déloyale”, en Vogel, L. (éd.), Dalloz répertoire de droit commercial. Dalloz encyclopédie juridique, Paris, Dalloz, 2004, §60.

${ }^{33}$ Civ. (3) 18.12.1972, D., 1973, p. 272, n. Mazeaud; Civ. (1) 11.5.1982, Gaz. Pal, 1982, 2, p. 612, n. Chabas; Viney, G. y Jourdain, P., Traité de droit civil. Les effets de la responsabilité, Paris, LGDJ, 2001, $2^{\mathrm{e}}$ éd., pp. 590-593; Conte (nota 1), \$76.

${ }^{34}$ Civ. (3) 2.7.1975, Bull. civ. III, No 233; Civ. (3) 23.1.1991, Bull. civ., III, No 28.

${ }^{35}$ Civ. (3) 27.6.2001, Bull. civ., III, N 83, RTD. Civ., 2001, p. 887, obs. Jourdain; Conte (nota 1), § 76. 
por la víctima, con independencia de la gravedad del comportamiento del demandado ${ }^{36}$; es decir, se busca restaurar la justicia conmutativa restituyendo a la víctima a su situación anterior al daño ${ }^{37}$. El límite es entonces el daño soportado por la víctima: esta se enriquecería injustificadamente si recibiera un monto de dinero superior al perjuicio ${ }^{38}$.

3.2. El principio de reparación integral está sustentado en la causalidad: se repara el perjuicio causado. La indemnización es la consecuencia última del hecho ilícito. El daño provoca un desplazamiento o movimiento patrimonial desde la víctima hacia el autor de aquel, quien deberá restablecerlo pagando a aquella un valor equivalente ${ }^{39}$. Este principio se refleja en la noción dominante de culpa civil -conducta anormal- y en su apreciación en abstracto, con prescindencia de los factores morales o psicológicos presentes en el autor del daño ${ }^{40}$.

3.3. Sin embargo, en la práctica la jurisprudencia francesa toma muy en cuenta la gravedad de la culpa especialmente para incrementar la reparación del daño moral, sancionando de manera indirecta a quienes cometen ilícitos intencionales o sumamente temerarios $^{41}$. Así, el dolo y la culpa lata producen efectos jurídicos particulares en la responsabilidad civil, contractual y extracontractual, siendo esta utilizada para prevenir la ocurrencia y castigar la perpetración de ciertos hechos, todo ello en beneficio de las víctimas. Esto es particularmente patente en las conductas desleales y anticompetitivas ${ }^{42}$, como se verá a continuación.

\section{La responsabilidad civil por prácticas desleasles y anticompetitivas}

4.1. La jurisprudencia acostumbra presumir el daño al mercado ${ }^{43}$ y la relación causal del mismo acto desleal, el que es por definición intencional ${ }^{44}$. El dolo ínsito en estas

${ }^{36}$ Civ. 24.5.1913, DP 1916, 1, p. 171; Civ. (2) 4.5.1964, JCP, 1965, Nº 14.140, n. Esmein.

${ }^{37}$ Civ. (2) 28.10.1954, Bull. civ., II, No 328, RTD. Civ., 1955, p. 324, obs. Mazeaud; Civ. (2) 22.1.2009, $\mathrm{N}^{\text {os }}$ 07-20.878 y 08-10.392, D., 2009, p. 1114, n. Loir; Le Tourneau (nota 1), §§ 8-20.

${ }^{38}$ Civ. (1) 22.11.2007, Bull. civ., No 06-14174.

39 Quézel-Ambrunaz (nota 22), pp. 454-455 y 463.

${ }^{40}$ Civ. (1) 20.7.1976, JCP, 1978, II, p. 18.793, n. Dejean de la Bâtie; Mazeaud y Chabas (nota 28), pp. 412-413; Conte (nota 1), §§ 16-17.

${ }^{41}$ Carbonnier, J., Droit civil. Les obligations, Paris, PUF, 2000, $22^{\mathrm{e}}$ éd., T. IV, pp. 505-506; Viney y Jourdain (nota 33), pp. 4-9.

42 Ballot-Léna (nota 6), Nos 5-10, 75 y 381. La pluralidad de intereses en juego explica que la responsabilidad civil involucra no solo a rivales sino a agentes situados en otros eslabones de la cadena productiva. Así sucede con los actos parasitarios, fuente de enriquecimiento injusto a costa del esfuerzo intelectual y material del perjudicado: Com. 30.1.1996, D., 1997, p. 232, obs. Serra.

${ }^{43} \mathrm{El}$ daño al mercado se desprende de la ilicitud intrínseca a la conducta desleal y de la necesidad de disuadir y sancionar al autor, pero el competidor debe probar su daño específico: Chagny (nota 6), pp. 466467; Ballot-Léna (nota 6), Nos 364 y 502-503.

${ }^{44}$ Com. 22.10.1985, D., 1986, IR, p. 339, obs. Serra; Com. 30.1.2001, D., 2001, p. 1939, n. Le Tourneau. 
conductas generalmente debe ser probado por el actor ${ }^{45}$. Pero una vez acreditado el juez presume el nexo causal y el daño ${ }^{46}$, de modo que incumbirá al demandado acreditar que concurrió una causal de justificación o una causa ajena ${ }^{47}$. Por tanto, el hecho de que el daño al mercado y la causalidad sean colegidos del acto de competencia desleal evidencia que la responsabilidad civil sirve como un medio tanto para prevenir y sancionar a sus autores como para facilitar la compensación de las víctimas ${ }^{48}$.

4.2. El dolo del agente es el principal índice para presumir la relación de causali$\operatorname{dad}^{49}$, pues el riesgo de dañar a terceros es consustancial a las conductas deliberadas: le mal résultant en principe du mal. En efecto, la intención de dañar normalmente revela el hecho de haber causado el perjuicio. Y esto es así porque, ceteris paribus, la probabilidad de causar un perjuicio es mayor si este resultado es querido por su autor que si este simplemente no toma el cuidado debido: En el caso del daño infligido intencionalmente, una persona elige actuar de modo que el daño ocurrirá. En el caso del daño infligido negligentemente, ella elige una acción que es inadecuada por cuanto el daño puede suceder. En ambos casos la producción del daño está vinculada a la elección ${ }^{50}$. En concreto, el dolo que caracteriza a los actos de competencia desleal devela un abuso de la libertad económica, del que se deduce un daño comercial que desencadena la responsabilidad civil ${ }^{51}$. La incidencia del dolo también se nota en que si el daño sufrido por la víctima procede tanto de una causa próxima de naturaleza cuasidelictual como de una remota de índole delictual, aquella es descartada y la responsabilidad se radica en esta ${ }^{52}$. Además, si uno entre varios coautores actúa dolosamente, aquel asume la responsabilidad en forma exclusiva ${ }^{53}$.

4.3. Asimismo, la jurisprudencia a veces reacciona frente a comportamientos dolosos ordenando que se indemnice la pérdida de una chance, como la disminución de la capacidad u oportunidades del demandante para competir o percibir las utilidades generadas por sus inversiones con la misma rapidez que previó al iniciar su negocio ${ }^{54}$, o incluso el mero "riesgo de daño", como el que resulta de la confusión de los bienes

${ }^{45}$ Civ. 14.3.1892, DP, 1892, 1, p. 523; Civ. (1) 11.7.1988, Bull. civ., I, No 237; Le Tourneau (nota $1), \S 36$.

${ }^{46}$ Habitualmente debe acreditarlos: Civ. (1) 11.7.1988, Bull. civ., I, No 237; Mazeaud y Chabas (nota 28), pp. 415 ss. y 660-661.

${ }^{47}$ Com. 9.10.2001, RTD. Civ., 2002, p. 304, obs. Jourdain; Vignon-Barrault, A., Intention et responsabilité civile, Marseille, PUAM, 2004, p. 147.

${ }^{48}$ Carval, S., La responsabilité civile dans sa fonction de peine privée, Paris, LGDJ, 1995, p. 132; Serra (nota 32), §§ 108-115; Ballot-Léna (nota 6), $\mathrm{N}^{\text {os }} 17$ y 113-114.

${ }^{49}$ Civ. (1) 5.4.2005, RTD. Civ., 2005, p. 607, obs. Jourdain.

${ }^{50}$ Gordley, J., Foundations of private law, Oxford, OUP, 2006, p. 197.

${ }^{51}$ Com. 22.10.1985, D., 1986, IR, p. 339, obs. Serra; Conte (nota 1), §§ 136, 215, 223.

52 Crim. 10.7.1952, JCP, 1952, II, p. 7272, n. Cornu.

${ }^{53}$ Civ. (1) 17.12.1996, Bull. civ., I, No 458; Vignon-Barrault (nota 47), pp. 349-350.

${ }^{54}$ Com. 20.10.1998, Revue de jurisprudence de droit des affaires, 1999, No 109. La jurisprudencia relaja el requisito de certidumbre del daño. Por ejemplo, concede la pérdida de la chance de adquirir clientela, daño que, debido a la libertad de competir, es de suyo incierto: Com. 17.7.2001, $\mathrm{N}^{\circ}$ 99-17.189. La jurisprudencia se adapta al contexto económico y considera las legítimas expectativas de los empresarios: Ballot-Léna (nota 6), §95. 
comercializados por la actora con los que vende el demandado ${ }^{55}$ o el peligro de que la imagen comercial del demandante sea afectada por los actos de descrédito ejecutados por su rival ${ }^{56}$. Igualmente, el que interfiere en contrato ajeno debe resarcir el lucro cesante consistente en las ganancias que el actor habría conseguido mediante el contrato que no pudo celebrar o que el deudor incumplió a raíz de dicha interferencia ${ }^{57}$. Adicionalmente, la jurisprudencia incrementa el quantum indemnizatorio considerando la gravedad de la culpa y las utilidades ilícitas obtenidas por el autor, las que suelen sobrepasar los daños causados a las víctimas. En la medida que la indemnización cubra las ganancias ilícitas aquella disuade de la comisión de estos hechos ${ }^{58}$.

4.4. En definitiva, la práctica judicial francesa en competencia desleal ilustra notablemente cómo la responsabilidad civil también atiende fines preventivos y retributivos, los que llegan a desplazar a la reparación ${ }^{59}$. La entidad de la culpa es un aspecto relevante para atribuir el deber de resarcir los daños patrimoniales y morales que estas conductas irrogan. La jurisprudencia exige una "culpa caracterizada" que no es sino una denominación alternativa del dolo, la negligencia inexcusable y la culpa grave, categorías que, más allá de ser confundidas con cierta regularidad ${ }^{60}$, revelan el abuso de la libertad de competir, circunstancia que impide justificar el perjuicio causado ${ }^{61}$. Luego, si bien oficialmente la jurisprudencia no exige dolo para atribuir responsabilidad por actos de competencia desleal ${ }^{62}$, definiendo esta como un comportamiento anormal o deficiente $^{63}$, en los hechos los jueces requieren la mala fe del autor del daño ${ }^{64}$ e incluso la intención de dañar en casos puntuales, como sucede con la denigración ${ }^{65}$ y la usurpación de nombres comerciales ${ }^{66}$.

4.5. La intencionalidad también es un factor que puede resultar gravitante para imputar la responsabilidad civil por ilícitos anticompetitivos y fijar el alcance del deber resarcitorio. Si bien las prácticas anticoncurrenciales son analizadas objetivamente, estas necesariamente entrañan dolo. Así, por ejemplo, el comportamiento predatorio envuelve

\footnotetext{
${ }^{55}$ Com. 27.2.1996, D., 1997, somm., p. 104, obs. Serra.

56 Cour Appel (CA) Paris 24.3.1995, D., 1996, somm., p. 252, obs. Izorche.

57 Com. 2.11.1993, RTD. Civ., 1994, p. 622, obs. Jourdain, JCP, 1995, I, 3853, p. 25, obs. Viney.

${ }^{58}$ CA Paris 10.7.1986, JCP, 1986, II, p. 20.712, n. Agostini.

59 Carval (nota 48), p. 145.

${ }^{60}$ Vignon-Barrault (nota 47), pp. 67-68.
}

${ }^{61}$ Starck, B.: Essai d'une théorie générale de la responsabilité civile consideré en sa double fonction de garantie et de peine privée, Paris, Rodstein, 1947, y; "Domaine et fondement de la responsabilité sans faute", RTD. Civ., 1958, pp. 475-515. Tunc, A., La responsabilité civile, Paris, Economica, 1989, 2e éd., pp. 153-155. Starck, B., Roland, H. y Boyer, L., Obligations. Responsabilité délictuelle, Paris, LITEC, 1996, 5éd., pp. 114 y 150 ; Viney y Jourdain (nota 15), pp. 563-564.

${ }^{62}$ Com. 18.4.1958, D., 1959, p. 87, n. Derrida; Com. 3.5.2000, D., 2001, somm., p. 1312, obs. Serra. Inicialmente se exigió dolo: Cass. Req. 9.11.1871, DP, 1871, 1, p. 211.

${ }^{63}$ CA Paris, 6.11.1989, D., 1990, p. 564, n. Thouvenin (el derecho a informar a los consumidores y a criticar a los competidores deviene denigratorio si es ejercido sin prudencia ni objetividad).

${ }^{64}$ Com. 7.4.1998, D., 1999, somm., p. 128, obs. Schmidt-Szalewski.

${ }^{65}$ Com. 6.3.1978, JCP, 1978, II, p. 19.001, n. Azéma.

${ }^{66}$ Com. 16.2.1977, Bull. civ., IV, No 51. 
la intención del autor de eliminar o debilitar a sus competidores mediante la venta a precios inferiores a los $\operatorname{costos}^{67}$. Esta intención suele ser presumida del mismo comportamiento irracional que envuelve la venta de bien a un precio que ni siquiera cubre los costos de producción ${ }^{68}$. Para acreditar una práctica predatoria deberá demostrarse que su autor tuvo la intención de eliminar a sus rivales. Este dolo puede ser colegido de la capacidad del agente para recuperarse de las pérdidas incurridas al vender bajo los costos. Esta habilidad puede deducirse de factores tales como la existencia de barreras de entrada al mercado y de la posibilidad del agente para producir volúmenes excesivos, destinados a satisfacer la mayor demanda creada por los precios predatorios ${ }^{69}$. Por tanto, aunque las conductas anticompetitivas son calificadas como ilícitos objetivos, la jurisprudencia a veces exige probar la intención de los autores de dañar al mercado ${ }^{70}$. Luego, estos ilícitos denotan un comportamiento abusivo que revela la intención de su autor de dañar tanto el mercado como a operadores comerciales específicos ${ }^{71}$.

4.6. Si bien la responsabilidad civil derivada de estas infracciones se basa en las reglas comunes y el litigio indemnizatorio gira en torno a la prueba del daño y del nexo causal $^{72}$, la sola imputación del deber de resarcir los perjuicios contribuye a prevenir futuras infracciones y a reprimir las conductas cometidas. Como argumenta Fasquelle, el derecho privado puede y debe jugar un papel complementario en la defensa de la libre competencia. Así como la autoridad pública está preocupada de los daños que estos hechos infligen a la economía, para ello procura hacerlos cesar y, antes bien, prevenir su perpetración, el juez civil busca que se indemnicen los perjuicios que tales ilícitos causan a víctimas particulares ${ }^{73}$.

4.7. En sentido análogo, Ballot-Léna muestra que existe una responsabilidad civil propia de los negocios, consagrada en los arts. 442 a 446 del Código de Comercio respecto de los actos anticompetitivos y en la jurisprudencia vis-à-vis la competencia desleal, lo que ha modificado el régimen común ya que persigue fines preventivos y punitivos junto con los indemnizatorios. En esta área los competidores luchan por conquistar nuevos mercados y el daño que unos sufren está permitido siempre que provenga del ejercicio de la libertad de competir. Debido a la trascendencia de los intereses envueltos, la responsabilidad civil juega un rol disciplinario para reprimir los actos de competencia desleal y prácticas anticompetitivas, v. gr., definiendo la culpa de modo estricto y presumiendo el vínculo causal. En suma, la responsabilidad por ilícitos de los negocios

${ }^{67}$ Cadiet, L. y Le Tourneau, P., “Abus de droit”, en Savaux, É. (ed.), Dalloz répertoire de droit civil. Dalloz encyclopédie juridique, Paris, Dalloz, 2008, T. I, § 101.

68 Com. 2003/707, 21.5.2003.

69 Cons. conc., Décis. N ${ }^{\circ}$ 04-D-10, 1.4.2004, UGC.

${ }^{70}$ Com. 22.10.2002, Sté Vidal, Contrats, conc., consom. 2003 No 2.

71 Malaurie-Vignal, M., Droit de la concurrence interne et communautaire, Paris, Sirey, 2008, $4^{\mathrm{e}}$ éd., pp. 208-209 y 255-256.

${ }^{72}$ Com. 1.3.1982, Bull. civ., $\mathrm{N}^{\circ} 76$.

${ }^{73}$ Fasquelle, D., "La réparation des dommages causés par les pratiques anticoncurrentielles”, en RTD. Com., pp. 763-794, especialmente pp. 765-768. 
forma un cuerpo normativo autónomo y coherente que los jueces interpretan de acuerdo con sus propios principios ${ }^{74}$.

Ballot-Léna contrasta el derecho de daños común con el que se aplica en el ámbito de la competencia. Destaca que en el primero la culpa prácticamente ha desaparecido, la noción de daño ha sido expandida y el requisito de la causalidad ha sido flexibilizado, mientras que en el segundo la culpa es indispensable para imputar y limitar la responsabilidad civil. Sin embargo, reconoce que los tribunales interpretan la culpa con mayor amplitud para proteger tanto a los competidores como a los consumidores. Asimismo, la jurisprudencia ordena indemnizar los perjuicios que producen los actos parasitarios procurando aplicar las normas con mayor eficiencia y flexibilidad ${ }^{75}$.

4.8. Si bien el dolo no agota las hipótesis de competencia desleal ${ }^{76}$, cuando el daño emana simultáneamente de hechos ilícitos según el estatuto general y de actos anticompetitivos o desleales, la jurisprudencia puede dar importancia a la gravedad de la culpa para calificar la conducta del demandado como la causa determinante del daño sufrido por el demandante. Luego, el aspecto objetivo de la culpa es la infracción de una regla preexistente, ya consista en la transgresión de los arts. 1382 y 1383 del Code, en una conducta desleal o en un ilícito anticompetitivo. En cambio, el aspecto subjetivo es la consciencia del autor acerca de las consecuencias de su hecho. Este elemento ha sido paulatinamente abandonado por los jueces en la medida que aprecian la culpa en abstracto, de acuerdo con un estándar objetivo de cuidado. Sin embargo, Ballot-Léna argumenta que el dolo debería ser más gravitante en el contexto de la competencia, ya que los agentes comerciales deberían actuar con consciencia de los efectos económicos que entrañan sus actos dolosos o negligentes. De este modo, a su juicio la imputación moral de la culpa sería apreciada en abstracto y la responsabilidad civil cumpliría una función de regulación del mercado ${ }^{77}$.

4.9. La culpa, concluye Ballot-Léna, es crucial en la responsabilidad civil derivada de los ilícitos de los negocios. El propósito de este régimen no se reduce a compensar a las víctimas sino que además pretende disuadir y castigar los hechos ilícitos desleales o anticompetitivos. Con todo, esta función punitiva incide en distintos elementos de la responsabilidad civil según la conducta involucrada. Tratándose de actos de competencia desleal, el énfasis recae en su intencionalidad; esto es, la culpa es definida de modo estricto, como dolo, presumiéndose de este la causalidad y el daño, los que son interpretados en forma laxa ${ }^{78}$. En cambio, en los ilícitos anticompetitivos la jurisprudencia acostumbra examinar con particular rigor tanto la existencia y cuantía del daño como la causalidad, siguiendo la opinión de expertos y efectuando un análisis económico ${ }^{79}$.

${ }^{74}$ Lefebvre, D., "La spécificité du droit commercial. Réflexion sur la place tenue, en droit privé, par le droit commercial par rapport au droit civil”, en RTD. Com., 1975, p. 285.

75 Ballot-Léna (nota 6), \$\$ 23-26, 34 y 37.

${ }^{76}$ Com. 6.5.1986, D., 1986, IR, p. 339, n. Serra.

77 Ballot-Léna (nota 6), $\$$ 40-45, 48, 56-58 y 75-76.

78 Ballot-Léna (nota 6), $\$$ 482-484.

${ }^{79}$ Ballot-Léna (nota 6), §§ 89-90. 


\section{La relevancia del dolo y la culpa lata en la responsabilidad aquiliana en general}

5.1. Más allá de los actos de competencia desleal y de las conductas anticompetitivas, la jurisprudencia francesa instintivamente modula la reparación de los perjuicios conforme con la gravedad de la culpa. Solo que no lo hace de manera explícita sino que camuflándola en la causalidad, para no aparecer transgrediendo ostensiblemente el principio de reparación integral. Así, mientras más grave sea la culpa del hechor, mayor será su repercusión causal en la producción de los daños. En cambio, los perjuicios derivados de una culpa más leve son calificados como indirectos o remotos y, por tanto, no susceptibles de resarcimiento ${ }^{80}$.

5.2. La influencia del dolo en la responsabilidad civil en Francia es particularmente notoria en casos de abuso del derecho. En efecto, las víctimas no son resarcidas por los perjuicios que padecen como consecuencia natural e inevitable del ejercicio normal de un derecho o libertad por el agente: este derecho o libertad es una causal de justificación del daño. Por el contrario, el daño proveniente del ejercicio abusivo del derecho o libertad de que se trate permite imputar la responsabilidad civil ${ }^{81}$.

5.3. Por cierto, el abuso del derecho también abarca conductas negligentes ${ }^{82}$. De hecho, solo ocasionalmente la jurisprudencia exige mala fe o dolo para dar por establecido un abuso del derecho ${ }^{83}$. Por regla general bastará que no existan razones serias que justifiquen una forma dada de ejercer un derecho, como el incumplimiento abrupto de un contrato ${ }^{84}$ o la utilización de un predio excediendo el nivel de molestias habituales propias de las relaciones de vecindad ${ }^{85}$. Sin embargo, el ejercicio de un derecho subjetivo de manera arbitraria, repentina o brutal entraña sin dudas un comportamiento doloso o, al menos, totalmente desconsiderado hacia los demás. La intención de dañar es el caso más conspicuo de abuso del derecho ${ }^{86}$. Así, el daño causado por quien ejerce un derecho sin perseguir un interés legítimo o serio ni alguna utilidad es un antecedente fáctico contundente para presumir que el agente actuó deliberadamente y, por tanto, para declararlo responsable ${ }^{87}$.

5.4. La jurisprudencia gala ofrece otros ejemplos de ejercicio doloso de un derecho, que dan lugar a la responsabilidad civil y que muestran que esta es la situación más patente de abuso: el arrendador que no acoge la petición de su arrendatario de terminar

${ }^{80}$ Viney, G., Le déclin de la responsabilité individuelle, Paris, LGDJ, 1965, No 365.

${ }^{81}$ Civ. (3) 23.5.1968, D., 1970, p. 463, n. Jestaz; Civ. (1) 9.4.1975, RTD. Civ., 1976, p. 781, obs. Durry; Civ. (1) 13.12.1994, Bull. civ., I, No 372; Tunc (nota 61), p. 153; Viney, G., Traité de droit civil. Introduction à la responsabilité, Paris, LGDJ, 1995, 2e éd., pp. 351-352; Viney y Jourdain (nota 15), pp. 563-564.

${ }^{82}$ Mazeaud y Chabas (nota 28), pp. 477-479 y 484; Cadiet y Le Tourneau (nota 67), \$\$ 3-5 y 27.

${ }^{83}$ Civ. (2) 18.11.1966, Bull. civ., II, No 906; Civ. (2) 16.7.1969, Bull. civ., II, No 256.

${ }^{84}$ Civ. (1) 7.10.1965 Bull. civ., I, N 519.

${ }^{85}$ Civ. (3) 4.2.1971, JCP, 1971, II, p. 16.781, n. Lindon: la jurisprudencia imputa responsabilidad estricta en casos de invasión de la propiedad ajena, excediendo el límite de las turbaciones normales entre vecinos, y atribuye responsabilidad por culpa si se interfiere con predios de terceros.

${ }^{86}$ Civ. (3) 25.6.1986, JCP, 1986, IV, p. 262.

${ }^{87}$ Civ. (2) 15.6.1988, Bull. civ., II, $\mathrm{N}^{\circ} 146$; Mazeaud y Chabas (nota 28), pp. 478 y ss. 
el contrato antes de la expiración del plazo fundada en que el segundo debe trasladarse de ciudad por motivos laborales, si la negativa del primero fue exclusivamente para fastidiar al actor y si a aquel no le causaba inconveniente alguno acceder a dicha solicitud, v. gr., porque podía arrendar el inmueble a un tercero sin mayor demora e incluso en condiciones más ventajosas ${ }^{88}$; la negativa del arrendador, por mera terquedad, a que su arrendatario efectúe remodelaciones en el inmueble arrendado, también envuelve un flagrante abuso del dominio ${ }^{89}$; la interposición de una acción judicial dolosamente, de mala fe o con imprudencia grave ${ }^{90}$; la negativa del marido a consentir en el divorcio solicitado por su esposa únicamente para perjudicarla ${ }^{91}$; el cobro de una multa convencional por el comprador de un establecimiento comercial ante el incumplimiento de una cláusula de no competir por el vendedor pero sin acreditar los perjuicios supuestamente sufridos $^{92}$. A estas ilustraciones puede añadirse el siguiente caso. La farmacia demandante proveía de medicamentos - sin exclusividad-a dos asociaciones paramédicas privadas, las que pusieron término repentinamente a la convención celebrada con la actora y contrataron el suministro exclusivo con otra farmacia. La actora reclamó los daños por el abuso del derecho de las demandadas a desahuciar el contrato. En el litigio se acreditó que las empresas demandadas terminaron dicho contrato por cuanto el cónyuge de la representante legal de la actora había competido en unas elecciones municipales contra el candidato que triunfó, quien ocupó el cargo de presidente de ambas demandadas. La Corte de Apelaciones de Aix-en-Provence acogió la demanda porque estimó que las demandadas actuaron dolosamente al perseguir la ruina de la demandante o, al menos, a forzarla a venderles su negocio a un precio vil. Empero, la Cour de Cassation anuló dicho fallo por considerar que las demandadas, lejos de abusar del derecho a desahuciar el contrato que las vinculaba con la actora, ejercieron su libertad a escoger el proveedor de su preferencia y a poner término al primer contrato conforme con el procedimiento acordado con la actora ${ }^{93}$. Como se aprecia, esta sentencia limitó el abuso al ejercicio doloso del derecho, cuya prueba es muy difícil.

5.5. Con todo, para una prestigiosa doctrina la teoría del abuso no sería aplicable a libertades como la de competir, pues -a diferencia de los derechos subjetivos- sus contornos son difusos. Así, los actos de competencia desleal no develarían un abuso del derecho sino un ejercicio excesivo de la aludida libertad ${ }^{94}$. Con todo, de contrario se argumenta que el ejercicio excesivo de una libertad puede ser sancionado como abuso

${ }^{88}$ Civ. (3) 22.2 .1968$, Bull. civ. III, No 71, D. 1968, p. 607 , note Ph. M.
${ }^{89}$ Civ. (3) 12.10 .1971$, D., 1972, p. 210.
${ }^{90}$ Civ. (2) 11.1 .1973$, Gaz. Pal, 1973, II, p. 710.
${ }^{91}$ Civ. (2) 21.4 .1982$, Gaz. Pal, 1983, 2, p. 591, n. Chabas (criticando la aplicación del abuso del derecho al ejercerlo de meras facultades y añadiendo que dicha doctrina abarca el ejercicio imprudente de un derecho).

92 Civ. (1) 19.11.1996, Bull. civ. I, No 404.

${ }^{93}$ Com. 5.7.1994, JCP , 1995, I, 3, p. 3828, obs. Fabre-Magnan (argumentando que el abuso exige que el derecho comprometido esté suficientemente delimitado: caso contrario debe utilizarse el concepto de culpa).

${ }^{94}$ CA Versailles, 19.1.1995, D., 1995, p. 259, obs. Serra; Serra (nota 32), § 89. 
del derecho, que es lo que acontece, sin ir más lejos, con la responsabilidad civil por actos de competencia desleal ${ }^{95}$. Por eso, más allá de esta controversia terminológica, el daño emanado del ejercicio de una libertad como la de competir -v. gr., la desviación de clientela- es legítimo, salvo que se utilicen medios deshonestos ${ }^{96}$. Los derechos subjetivos son relativos y, por ende, no deben ser ejercitados con el propósito de dañar a terceros, mediante la ejecución de conductas que, cual ocurre con las prácticas desleales y anticompetitivas, comportan el abuso del derecho o libertad de competir ${ }^{97}$. En este sentido, Jean Carbonnier argumentó que el ejercicio de una libertad puede justificar la realización de actos dañinos, como es la ruina de los competidores vencidos por sus rivales, mientras que el daño que fluye del abuso del derecho o libertad queda desprovisto de toda justificación. Este abuso puede residir en el fin buscado por el autor, sobre todo en su intención de dañar, o en los medios utilizados, como acontece con los actos desleales que vulneran la moralidad de los negocios ${ }^{98}$.

5.6. Igualmente, como sostiene Van-Karila, actividades de indudable valor social, aunque eventualmente dañinas -como la competencia comercial-, no deberían quedar sujetas al principio neminen laedere sino que solo debería responder de sus efectos perjudiciales quien abusa o excede la libertad que subyace a dicha labor ${ }^{99}$. Como dijera décadas antes Boris Starck, si el derecho a la seguridad de la víctima colisiona con la libertad de actuación del agente, los daños puramente patrimoniales $-y$ también los daños morales- que este pueda causar a aquella son lícitos en tanto cuanto representen un efecto natural e inexorable del ejercicio del derecho subjetivo o libertad individual pertinente. Así, la competencia comercial ruda, pero limpia, permite al ganador adquirir la clientela de sus contrincantes perdedores sin que por ello estos tengan derecho a una indemnización ${ }^{100}$; a menos que, como afirmara René Savatier, el agente hubiese abusado de la facultad de dañar que es inherente al derecho o libertad de que es titular ${ }^{101}$.

5.7. En suma, como sostiene Vignon-Barruault, el ejercicio de una libertad o derecho deviene abusivo si su titular actúa con la intención de dañar, como un fin o como un medio para enriquecerse ${ }^{102}$. Luego, cuando este "derecho a dañar" (el ejercicio de un derecho o libertad individual como causal de justificación del daño) integra la actividad pertinente, como es el caso de la competencia, la víctima solo tiene derecho a ser resarcida si el agente ha abusado de su derecho o libertad. En cambio, en la generalidad de

\footnotetext{
${ }^{95}$ Cadiet y Le Tourneau (nota 67), $\$ \$ 9-10$.

96 Serra (nota 32), §32.

97 Cadiet y Le Tourneau (nota 67), $\S 14-15$.

98 Carbonnier (nota 41), pp. 421-422. El abuso del derecho a competir incluye actos desleales (por medios abusivos que afectan la competencia entre comerciantes) y anticompetitivos (que suprimen o restringen la libre competencia): Schaeffer, E., "L'abus dans le droit de la concurrence", en Gaz. Pal, 1981,

${ }^{99}$ De van Karila, J., "The droit to nuire", en RTD. Civ., 1995, pp. 533-558, especialmente pp. 533-534.

100 Starck (1958, nota 61), p. 505.

101 Savatier, R., Traité de la responsabilité civile en droit français, Paris, LGDJ, 1951, T. I., pp. 48 y ss.

102 Vignon-Barrault (nota 47), pp. 150-151.
} 2, doctrine, pp. 401-408. 
los casos -v. gr., accidentes de tránsito, relaciones de vecindad, etc.-, como el daño es solo una consecuencia y no forma parte de la actividad que lo genera, el sistema jurídico otorga a las víctimas un derecho preponderante a ser indemnizadas ${ }^{103}$.

\section{La influencia de la doctrina en la concepción amplia de la responsabilidad civil}

6.1. La doctrina civil francesa ha contribuido decididamente a la comprensión de los fines de la responsabilidad civil cimentada en la culpa. Boris Starck identificó dos funciones de este instituto: de garantía o protección de las víctimas que padecen daños en su integridad física o en sus bienes corporales, muebles e inmuebles, lo que da lugar a la indemnización integral de los perjuicios aun cuando estos resulten del ejercicio de un derecho o libertad por el demandado; y de pena privada de los daños puramente patrimoniales y morales, acorde a la gravedad de la culpa del autor que debe acreditarse en el proceso. Starck sostuvo que la responsabilidad civil supera a la responsabilidad penal tanto en la eficiente disuasión y represión de los comportamientos dañinos como en la capacidad para adaptarse con flexibilidad a las necesidades de la vida social ${ }^{104}$.

6.2. Con todo, Starck no justificó el tratamiento diferenciado de las diversas clases de daños. Así, no es claro por qué los intereses estrictamente económicos solo desencadenan responsabilidad cuando han sido lesionados de forma dolosa, no obstante que pueden ser un activo mucho más valioso que un bien corporal cuya destrucción o deterioro da lugar a responsabilidad por mera negligencia o incluso sin culpa. André Tunc apunta que una razón para ello es que los daños puramente patrimoniales por regla general emanan del ejercicio de la libertad de competir, es decir, son un efecto colateral e inevitable de una actividad socialmente beneficiosa, de suerte que los rivales afectados solo tendrían derecho a ser resarcidos si tales daños emanan del abuso de la libertad económica que se traduce en una conducta ejecutada con intención de dañar o con suma imprudencia ${ }^{105}$. Así, por ejemplo, los actos de competencia desleal son deliberados o, como señalaran Starck, Roland y Boyer, involucran una "culpa caracterizada" que representa un comportamiento abusivo y que se distingue de los casos en que el daño está justificado por ser una consecuencia natural e inexorable de la competencia limpia aunque ruda. En buenas cuentas, la culpa calificada permite al juez sopesar dos valores en constante tensión: la libertad de competir y la protección de la víctima ${ }^{106}$.

6.3. De las diversas fisonomías que adopta la culpa - a saber, infracción del deber de cuidado, negligencia, violación de un derecho subjetivo y abuso del derecho- ${ }^{107}$, en casos como los de la competencia desleal se aplican el dolo o la culpa lata, porque ambos son indiciarios del abuso del derecho. En concreto, la jurisprudencia exige una culpa calificada como requisito de la indemnización de los daños puramente patrimoniales

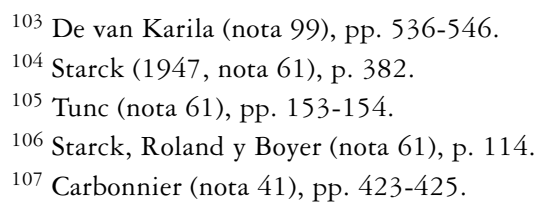


y morales, mientras que solo requiere culpa leve para imputar responsabilidad por los daños físicos a las personas y a sus bienes corporales ${ }^{108}$. Es más, como destaca el comparatista alemán Gerhard Wagner, a pesar de que la mayoría de la doctrina francesa niega las funciones de garantía y pena de la responsabilidad civil, entre otros motivos porque la primera de ellas es propia de la responsabilidad estricta que se aplica por los daños físicos a la persona y a su propiedad tangible, en los hechos la jurisprudencia reconoce la distinción entre ambos roles o fines de la responsabilidad civil ${ }^{109}$. Luego, por más detractores que tiene, las ideas de Starck tienen una clara concreción en la práctica jurisprudencial francesa. La responsabilidad civil no es un medio exclusivamente compensatorio e incluso el carácter meramente restitutorio de esta institución podría ser una simple quimera ${ }^{110}$.

6.4. En este sentido, aun cuando no es factible escrutar el pensamiento de los jueces, con frecuencia la reparación es calculada en función de la culpa cometida por el autor del daño ${ }^{111}$, especialmente tratándose de daños puramente patrimoniales ${ }^{112}$. En efecto, la jurisprudencia francesa reconoce a las víctimas el derecho a la indemnización de los daños materiales, especialmente del lucro cesante, aunque estos no deriven de la lesión a su integridad -física o psíquica- ni de un perjuicio a sus bienes corporales. Vale decir, en principio la reparación del "daño puramente patrimonial” no está supeditada, a diferencia de los sistemas angloamericanos y alemán, a la comisión de conductas dolosas, ordenándose aunque él derive de actos negligentes. La forma de limitar la responsabilidad por esta clase de daños es exigiendo que estos sean ciertos y directos ${ }^{113}$. Sin embargo, esta clase de daños suele emanar de actos deliberados, en particular, de la competencia desleal ${ }^{114}$. Pues bien, como este tipo de daños con frecuencia emana de delitos civiles consistentes en el ejercicio abusivo de un derecho subjetivo o libertad individual, en los hechos el derecho francés no dista mucho de sus pares inglés y alemán.

6.5. Asimismo, Starck abogó por el abierto reconocimiento de las funciones preventiva y retributiva de la responsabilidad civil mediante la consagración de los "daños punitivos" (indemnización punitiva) y el destino de las multas civiles al erario fiscal, junto con conferir a las víctimas el derecho a la restitución de las ganancias ilícitamente

108 Starck, Roland y Boyer (nota 61), p. 150.

${ }^{109}$ Wagner, G., "Comparative tort law”, en Reimann, M. \& Zimmermann, R. (eds.), The oxford handbook of comparative law, Oxford, OUP, 2006, p. 1017.

${ }^{110}$ Starck, Roland y Boyer (nota 61), No 82.

${ }^{111}$ Granier, J., “Quelques réflexions sur l'action civile”, en JCP, 1957, I, Nº 1386.

112 Lapoyade-Deschamps, C., "La réparation du préjudice économique pur en droit français, en Revue International de Droit Comparé, 1998, pp. 379 y ss.

113 Civ. 28.7.1965, D., 1965, p. 777, n. Esmein; Mazeaud y Chabas (nota 28), pp. 415 y 660-661. Por ejemplo, deben indemnizarse las utilidades que el actor habría obtenido de un contrato que, debido a la actuación dolosa o culpable del demandado, no se celebró: Civ. (2) 18.12.1963, Bull. civ., 1963, II, Nº35.

${ }^{114}$ Com. 18.12.1986, D., 1987, IR, p. 19. Quien por un acto desleal hace perder al rival la oportunidad de conquistar un mercado debe resarcirlo: Com. 3.5.1979, Bull. civ., IV, No 137, p. 138; Viney y Jourdain (nota 15$)$, pp. 30-33 y 93 . 
habidas por los autores del daño, es decir, castigando la denominada "culpa lucrativa"115. La pena privada, aseveró, no es una reminiscencia o un fantasma del pasado sino que una fuerza viva de la responsabilidad civil ${ }^{116}$. Otros juristas también han propuesto que la indemnización punitiva sea pagada a la víctima como compensación por el servicio que presta a la comunidad al reclamar daños contra quienes cometen comportamientos antisociales $^{117}$.

6.6. En la misma línea indicada, Chagny postula la necesidad de oficializar la pena privada para impedir que los jueces continúen aplicándola de manera arbitraria e impredecible, así como también para disuadir eficazmente a los potenciales infractores ${ }^{118}$. Chagny admite el rol punitivo de la responsabilidad civil en la jurisprudencia tratándose tanto de actos de competencia desleal o parasitarios como de ilícitos anticompetitivos, aun cuando respecto de estos últimos ello es menos notorio, ya que generalmente son objeto de una sanción administrativa que antecede al juicio indemnizatorio. En ambos ámbitos la responsabilidad civil opera como una pena privada: el interés reside no tanto en la víctima como en el autor del daño. Los tribunales consideran la gravedad de la conducta del autor y, de ese modo, alteran las reglas generales de la responsabilidad civil, e incluso intentan neutralizar las ganancias obtenidas por el autor del hecho ilícito ${ }^{119}$.

En particular, Chagny estima que una sanción civil sería una vía más eficiente para castigar las conductas anticompetitivas que la clásica condena simbólica a pagar "un franco" ${ }^{20}$. Aun cuando Chagny reconoce que el derecho de obligaciones persigue fines preventivos y retributivos modestos, dentro de los límites que impone el principio de la reparación integral, destaca el hecho de que sus reglas pueden ser interpretadas y aplicadas con flexibilidad a las nuevas realidades que surgen con la evolución económica, social y tecnológica ${ }^{121}$. La responsabilidad civil es un medio relevante para proteger la libertad de competir, sobre todo por la generalidad de sus reglas acerca de la culpa y el hecho ilícito, permitiendo al juez resolver casos que exceden las regulaciones especiales. El derecho civil es así indispensable para llenar vacíos, pues puede ser acomodado a las más variadas situaciones fácticas ${ }^{122}$.

115 Starck, Roland y Boyer (nota 61), No 1.335.

116 Starck (1947, nota 61), p. 359.

117 Grare, C., Recherches sur la cóberence de la responsabilité délictuelle. L'influence des fondements de la responsabilité sur la réparation, Paris, Dalloz, 2005, No 482.

118 Chagny, M., "La notion de dommages et intérêts punitifs et ses répercussions sur le droit de la concurrence", en Lectures plurielles de l'article 1371 de l'avant-projet de réforme du droit des obligations, JCP, 2006, I, No 149 .

119 CA Paris, 20.3.1995, Gaz. Pal, 1995, 2, somm. p. 473.

${ }^{120}$ Chagny (nota 6), pp. 522-528.

${ }^{121}$ Chagny (nota 6), pp. 115-120. De hecho, la adaptabilidad del derecho privado es una razón para preferir las reglas de responsabilidad civil consagradas en el Code contra los actos de competencia desleal en lugar de una ley especial. Los jueces franceses solo necesitan de normas generales para ponderar los intereses en conflicto, definir los comportamientos desleales y sancionar la vulneración de los deberes que demarcan el ejercicio de la libertad de competir: Chagny (nota 6), pp. 233-234.

122 Chagny (nota 6), pp. 275-280; Le Tourneau (nota 30), p. 506. 
6.7. De manera similar, Carval estima necesario explicitar la función punitiva de la responsabilidad civil ${ }^{123}$. Prologando el trabajo de esta autora, Geneviève Viney reconoce un rol punitivo natural y necesario en ciertos sectores de la responsabilidad civil en los que resulta particularmente complejo avaluar los daños. Una de estas áreas es la competencia, donde la pena privada aparece como una alternativa a las sanciones criminales, cuya aplicación exige atender tanto a la entidad de la conducta del autor del daño como a las utilidades ilícitas obtenidas por este.

La responsabilidad civil, aduce Carval, permitiría regular la competencia y la culpa sería el medio por el que el juez puede definir si existe un acto de competencia desleal generador del deber de reparar el daño causado. En general, el daño infligido entre adversarios es lícito e incluso incentivado por el sistema jurídico. Por eso, como declara una jurisprudencia constante, no existe propiedad sobre la clientela o las cuotas de mercado, de suerte que la pérdida de ella es un efecto natural del ejercicio de la libertad de competir: esta es causa del éxito de unos y del fracaso de otros. El daño, como la captura de clientela ajena, solo es indemnizable si el competidor demandado se valió de medios desleales dirigidos a desviarla y atraerla para $s^{124}$.

Sin embargo, la responsabilidad civil no es un mecanismo eficaz para obligar al autor a restituir las ganancias ilícitas obtenidas mediante sus actos desleales o anticompetitivos: la indemnización no puede superar el daño sufrido por la víctima. Por eso, Carval cree necesario contar con una acción restitutoria especial, para disuadir la perpetración de estos actos intencionales, dejando intacta la función resarcitoria de la responsabilidad civil ${ }^{125}$.

Asimismo, Carval considera que la posibilidad de imputar responsabilidad administrativa y civil no desalienta suficientemente la realización de dichos actos ilícitos, pues quienes los perpetran pueden obtener utilidades que superan con creces el riesgo de una eventual condena resarcitoria. Agrega que la jurisprudencia rara vez obliga al demandado a restituir las ganancias ilícitas, tendiendo a limitar la reparación al daño sufrido por la víctima ${ }^{126}$. Ante esta realidad, Carval exhorta a la jurisprudencia a admitir

123 Carval (nota 48), passim.

${ }^{124}$ CA Paris, 5.3.1987, D., 1988, somm. 180, obs. Serra (la adquisición de los clientes de un competidor es permitida si no transgrede los usos mercantiles honestos); Com. 21.6.1988, Bull. civ., IV, N 210 (incumbe al juez determinar si la infracción de una regla es un acto desleal); CA Paris 27.5.1992, D., 1993, somm. 155, obs. Izorche; CA Paris, 3.7.1996, RJDA, $\mathrm{N}^{\circ} 1422$ (el cobro de precios inferiores a los del rival no es un acto desleal sino expresión de la libertad de precios salvo que riñan con las costumbres mercantiles, como si se fija un precio irrisorio); CA Paris, 9.6.1999, D., 2000, somm. 325, obs. Auguet (la venta a clientes de un competidor sin valerse de métodos desleales está justificada en la libertad comercial); Com. 24.10.2000, Bulletin rapide de droit des affaires, 2000, $\mathrm{N}^{\circ} 21$, p. 12, obs. Serra (la formación por antiguos trabajadores de la actora de una sociedad competidora no es por sí solo un acto desleal); Serra, Y., "La validité de la clause de non-concurrence", en D., 1987, Chronique, pp. 113-116; Izorche, M., "Les fondaments de la sanction de la concurrence déloyale et du parasitisme”, en RTD. Com., 1998, pp. 17-52; Auguet, Y., Droit de la concurrence, Paris, Ellipses, 2002, p. 19; Serra (nota 32), §§ 1-5, 7-10, 22-28 y 191.

125 Carval (nota 48), pp. 121-130/158-163; Chagny (nota 6), pp. 527-528; Ballot-Léna (nota 6), $\mathrm{N}^{\text {os }}$ 491 y 504.

${ }^{126}$ Com. 14.2.1984, D., 1985, somm. 86. 
derechamente el rol punitivo de la responsabilidad civil por actos de competencia desleal e ilícitos anticompetitivos, condenando a los infractores a restituir los beneficios mal habidos e indemnizar los perjuicios. Sin embargo, la actio de in rem verso es inconveniente porque es subsidiaria (de modo que no puede ser entablada si la víctima dispone de otra acción, como sucede en estos casos en que se cuenta con la acción de indemnización de perjuicios) y porque su límite es el empobrecimiento de la víctima y no-que es lo que realmente interesa- el enriquecimiento del demandado. Carval propone reformar la acción restitutoria privándola de su naturaleza subsidiaria y limitándola al monto del lucro obtenido por el demandado.

En lugar de presumir el daño de las mismas conductas desleales ${ }^{127}$, Carval argumenta que la jurisprudencia debería reconocer que la restitución es una pena privada disponible contra la culpa lucrativa ínsita en las conductas dolosas o gravemente negligentes, cuyos autores deberían ser condenados a restituir las utilidades ilícitas. Los fallos deben explicar las razones que conducen a imputar una pena privada y tienen que anularse todos aquellos que utilicen la indemnización del daño moral como una pena soterrada ${ }^{128}$.

6.8. Análogamente, Vignon-Barrault denuncia la contradicción que importa desconocer oficialmente los fines disuasivos y retributivos de la responsabilidad civil no obstante que se acepta implícitamente que la gravedad de la culpa repercute de modo directo en el monto indemnizatorio. Sugiere circuncribir la función punitiva de la responsabilidad civil a los ilícitos lucrativos, como las conductas anticompetitivas y desleales $^{129}$, cuyo autor persigue dañar a otros como medio para enriquecerse, e imponer una pena proporcional a la seriedad del hecho ${ }^{130}$. Otros académicos proponen aplicar también la indemnización punitiva en el ámbito de la responsabilidad civil derivada del ejercicio de la libertad de prensa ${ }^{131}$ y en materia medioambiental ${ }^{132}$.

6.9. En cambio, para juristas como Christophe Quézel-Ambrunaz, la indemnización punitiva es ajena a la responsabilidad civil. Esgrime este autor que el hecho ilícito es causa del daño y de la obligación de repararlo, pero solo es motivo u ocasión para imponer una pena privada. Esto es, la indemnización punitiva no nace del delito civil sino de una norma legal de naturaleza penal. Que la fuente de la sanción civil difiere de la fuente del deber resarcitorio es demostrado por el hecho de que la indemnización punitiva es calculada considerando factores ajenos al perjuicio, en particular, la gravedad de la culpa del agente. Es más, la causalidad como elemento de la responsabilidad civil

${ }^{127}$ V. gr., el riesgo o posibilidad de confundir a los consumidores es colegido del acto de competencia desleal (Com. 25.11.1986, Bull. civ., IV, $\mathrm{N}^{\circ}$ 218); el daño patrimonial o incluso moral se deduce de la infracción de una cláusula de no competir (Com. 17.1.1979, Bull. civ., IV, No 42).

${ }^{128}$ Carval (nota 48), pp. 131-133, 144-146, 158-163, 330-335 y 360-361.

${ }^{129}$ Lasserre-Kiesow, V., "La promotion des sanctions civiles en droit des pratiques anticoncurrentielles", en D., 2007, Chronique, pp. 2116-2119.

${ }^{130}$ Vignon-Barrault (nota 47), pp. 380-384.

${ }^{131}$ Dreyer, E., "La perversion du référé en matière de prense", en JCP, 2007, I, No 171 (indicando que, en este campo, la distinción entre derecho civil y penal se difumina, si es que no pierde toda trascendencia).

${ }^{132}$ Rousseau, M., "La dificulté d'établir la responsabilité civile de l'entreprise en matière d'environnement", en JCP, supplément aux Cahiers du droit de l'entreprise, 1999, $\mathrm{N}^{\circ} 1$, pp. 19 y ss. 
es inconciliable con la indemnización punitiva ${ }^{133}$. Estos no se fundan en los arts. 1382 y 1383 del Code, ya que estas reglas consagran el principio de reparación integral y en modo alguno la pena privada. La indemnización punitiva es una institución autónoma de la responsabilidad civil y esta no comprende como una de sus tareas la retribución ${ }^{134}$. Además, en contra de la idea de restablecer la función punitiva de la responsabilidad civil -cuyo apogeo se alcanzó con la promulgación del Code, quedando la causalidad relegada a un segundo plano ${ }^{135}$ - para acercarla a la responsabilidad moral, Quézel-Ambrunaz sostiene que la objetivación de la responsabilidad civil y el abandono de la culpa moral son procesos históricos sin marcha atrás. Por eso, como afirmaran Georges Ripert y Henri Mazeaud, lo que interesa es reparar el daño infligido a la víctima y la causalidad se erige en el elemento central de la responsabilidad civil, desplazando a la culpa ${ }^{136}$.

Asimismo, se insiste que la responsabilidad civil cumple una muy modesta función preventiva, en parte por la masificación de los seguros y en parte porque los daños generalmente son un efecto de conductas defectuosas o erróneas - de cosas o de terceros- y solo por excepción derivan de comportamientos deliberados. Por eso, el razonamiento judicial debe partir del daño causado a la víctima y no de la culpa del autor. En todo caso, la reparación integral es una sanción que cumple un rol normativo o moralizador ${ }^{137}$.

De hecho, la responsabilidad por culpa no es más cercana a la moral que la responsabilidad estricta. Además, para hacer frente a los comportamientos constitutivos de culpa lucrativa, se acusa la inconvenencia de otorgar a las víctimas cantidades de dinero superiores al perjuicio a título de pena, porque ello propendería a su enriquecimiento injusto. La solución consistiría en forzar al demandado a pagar una indemnización proporcional al movimiento de valor patrimonial cuya conducta causó, incluyendo un monto equivalente al uso del bien de dominio de la víctima al margen del destino que esta haya querido darle. Por ejemplo, si el demandado ocupó ilícitamente una propiedad de la actora, la indemnización debería incluir el daño emergente (representado por los gastos) y el lucro cesante (las rentas que el demandado se ahorró de pagar), aun cuando el dueño no haya tenido la intención de dar en arrendamiento su activo.

En resumen, las propias reglas de la responsabilidad civil podrían ser interpretadas y aplicadas de manera tal que permitan neutralizar la culpa lucrativa, sin necesidad de introducir la indemnización punitiva ni de crear un estatuto especial ${ }^{138}$. Con todo, en apoyo de la incorporación de aquella se argumenta que la responsabilidad civil

133 Quézel-Ambrunaz (nota 22), pp. 498 y 507.

134 Jault, A., La notion de peine privée, Paris, LGDJ, 2005, $\mathrm{N}^{\mathrm{os}} 117$ y 119.

135 La extensión de la responsabilidad civil dependía esencialmente de la culpa como fundamento de equidad, desplazando a la causalidad: Marty, G., "La relation de cause à effet comme condition de la responsabilité civile”, en RTD. Civ., 1939, pp. 685 y ss.

${ }^{136}$ Ripert, G., Le règle morale dans las obligations civiles, Paris, LGDJ, 1949, $4^{\mathrm{e}}$ ed., N $\mathrm{N}^{\mathrm{o}} 115$; Mazeaud, H., "La 'faute objective' et la responsabilité san faute", en D., 1985, Chronique, p. 13; Lambert-Faivre, Y., "L'évolution de la responsabilité civile: d'une dette de responsabilité à une créance d'indemnisation", en RTD. Civ., 1987, p. 1; Quézel-Ambrunaz (nota 22), p. 528.

${ }^{137}$ Roujou de Boubée, M-E., Essai sur la notion de réparation, Paris, LGDJ, 1974, p. 54.

138 Quézel-Ambrunaz (nota 21), pp. 533-541. 
evoluciona de forma cíclica y no lineal, oscilando entre la reparación y la retribución ${ }^{139}$. Esta última función, se añade, recuperaría en la presente centuria el sitial que tuvo en la época decimonónica ${ }^{140}$.

\section{DERECHO CHILENO}

\section{La función oficial de la responsabilidad civil extracontractual. La limitada trascendencia del dolo}

1.1. En nuestro país la responsabilidad aquiliana se basa en la infracción del deber de no dañar a otro imprudente o deliberadamente. Su rol esencial, fundado en la justicia correctiva, es indemnizar el daño sufrido por la víctima, restituyéndola al estado anterior al hecho ${ }^{141}$. Además, del principio de reparación integral-calificado como la idea directriz del sistema indemnizatorio chileno ${ }^{142}$ - se sigue que la extensión del resarcimiento depende de la magnitud del perjuicio, con prescindencia de si este proviene de un delito o de un cuasidelito civil ${ }^{143}$.

1.2. La relevancia del dolo -y también de la culpa grave- se circunscribiría a la órbita contractual, según lo estatuido en el art. 1558 del Código Civil. En realidad, la única importancia que la doctrina tradicional concede al dolo en el ámbito extracontractual atinge al daño moral. En efecto, en la práctica jurisprudencial el dolo y la culpa lata inciden en una mayor indemnización del daño moral, lo que denota que la responsabilidad extracontractual también atiende un fin retributivo ${ }^{144}$. En no pocas ocasiones la gravedad de la culpa y del comportamiento del demandado son factores que los jueces

139 Viney (nota 82), Nº 218.

${ }^{140}$ Graëve, L., Essai sur le concept de droit de punir en droit interne, Lyon III, thèse, 2006, N ${ }^{\circ} 1325$.

${ }^{141}$ CS, 26.11.1970, Revista de Derecho y Jurisprudencia (RDJ), T. 67, sec. $1^{\mathrm{a}}$, p. 535; CS, 24.1.2002, Gaceta Jurídica $(G J), \mathrm{N}^{\circ} 259$, p. 38; Alessandri, A., De la responsabilidad extracontractual en el derecho civil chileno, Santiago, Imprenta Universitaria, 1943, pp. 28, 533 y 547; Gatica, S., Aspectos de la indemnización de perjuicios por incumplimiento del contrato, Santiago, Editorial Jurídica de Chile, 1959, pp. 58-59; Domínguez, R., "Consideraciones en torno a la noción de daño en la responsabilidad civil. Una visión comparatista", en Revista de Derecho Universidad de Concepción, 1990, No 188, p. 135; Díez, J., El daño extracontractual. Jurisprudencia y doctrina, Santiago, Editorial Jurídica de Chile, 1997, p. 159; Barros, E., Tratado de responsabilidad extracontractual, Santiago, Editorial Jurídica de Chile, 2006, pp. 37-38 y 215-216; Tapia, O., De la responsabilidad civil en general y de la responsabilidad delictual entre los contratantes, Santiago, Editorial LexisNexis, 2007, $3^{\mathrm{a}}$ ed., p. 375; Domínguez, C., "El principio de reparación integral del daño y su contenido: algunas consecuencias para el derecho chileno", en Departamento de Derecho Privado Universidad de Concepción (coord.), Estudios de Derecho Civil V, Santiago, Editorial Abeledo Perrot - Legal Publishing, 2010, pp. 671-685.

142 Domínguez, R., "Los límites al principio de reparación integral", en Revista Chilena de Derecho Privado, 2010, No 15 , p. 27.

143 [E]n materia de responsabilidad cuasidelictual, la culpa no tiene grados, ni admite diferencias: hay culpa o no la hay, pues lo único que importa para los efectos del pleito, es el monto de los daños, y es esto lo que regula la indemnización, con entera prescindencia de la gravedad de la culpa: CS, 12.8.1953, RDJ, T. 50, sec. $1^{\text {a }}$, p. 288.

${ }^{144}$ Alessandri (nota 141), p. 546; Domínguez (nota 141), p. 133; Barros (nota 141), pp. 166-167 y 308-309. 
civiles toman en serio al momento de fijar el quantum del daño moral; solo que, como sus pares franceses, generalmente no explicitan esta consideración punitiva ${ }^{145}$.

\section{La trascendencia del dolo en la responsabilidad aquiliana}

2.1. Ahora bien, un sector minoritario de la doctrina civil chilena contemporánea plantea que el dolo debe tener una repercusión causal y, por tanto, en la extensión de la responsabilidad aquiliana. Según esta tesis, el autor del hecho ilícito doloso debería responder de todos los daños que se siguen de su conducta, aun si escapan al curso normal de los acontecimientos ${ }^{146}$. Luego, quien perpetra un delito debería indemnizar todos los perjuicios directos, previsibles e imprevisibles, que el modelo de comportamiento aplicable habría contemplado a la época de perpetrar el hecho ${ }^{147}$.

2.2. Sin embargo, este argumento no pretende instaurar la indemnización punitiva, ya que ello, sin dudas, requiere de una reforma legal, la que en todo caso solo podría plantearse una vez que se tuviera certeza de que ello no contraviene la Constitución ${ }^{148}$. Por el contrario, la tesis que aquí se sigue únicamente sugiere que, cuando la víctima ha sido lesionada por un hecho doloso o en extremo descuidado, la responsabilidad debería abarcar todos los daños que ella sufrió como consecuencia directa, por remotos que ellos sean. En cambio, la responsabilidad por conductas meramente negligentes debería estar limitada a los daños directos previsibles por el patrón de comportamiento respectivo, quedando así excluidos los perjuicios imprevisibles ${ }^{149}$.

2.3. La jurisprudencia chilena no ha reconocido este planteamiento. Pero sí ha declarado que la previsibilidad es inherente a la negligencia ${ }^{150}$ y que el autor de un cuasidelito está obligado a indemnizar solamente los perjuicios directos previsibles al tiempo del hecho ${ }^{151}$. Esta jurisprudencia es doblemente interesante. Por un lado, porque ella indica que la responsabilidad civil extracontractual no se extiende a todos los perjuicios directos emanados de conductas negligentes, como postula la doctrina tradicional $^{152}$,

${ }^{145}$ CS, 14.9 .1987$, RDJ, T. 84, sec. 4a, p. 137; CS, 2.12.1998, FM, No 481, p. 2737; CS, 9.12.2013, rol 314-2010; CS, 3.12.2015, rol 29.365-2014.

146 Barros (nota 141), pp. 91-92, 404-405 y 989.

${ }^{147}$ Banfi, C., "Por una reparación integral del daño extracontractual limitada a los hechos dolosos o gravemente negligentes”, en Revista Ius et Praxis, 2012, Año 18, No 2, pp. 3-32.

${ }^{148}$ Larraín, C., “Aproximación a los punitive damages”, en Pizarro, C. (coord.), Estudios de Derecho Civil IV, Santiago, Editorial Legal Publishing, 2009, pp. 707-719.

${ }^{149}$ Banfi (nota 147) y Banfi, C., Responsabilidad civil por competencia desleal. Estudio de derecho chileno y comparado, Santiago, Editorial Thomson Reuters-Legal Publishing, 2013, passim. "Mientras la responsabilidad civil tenga como límite la total entidad del daño causado, no creemos que pueda hablarse propiamente de pena civil...sino tan solo... como criterio de valoración de los daños y perjuicios, que excluye toda posible moderación": De Cossío y Corral, A., El dolo en el derecho civil, Madrid, Editorial Revista de Derecho Privado, 1955, pp. 123-124.

${ }^{150}$ CS, $17.10 .1972, R D J$, T. 69 , sec. $4^{\text {a }}$, p. 168 ; CS, $12.8 .1981, R D J$, T. 78, sec. $4^{\text {a }}$, p. 120.

${ }^{151}$ CS, 24.3.2004, GJ, No 285, p. 138; CS, 12.6.2015, rol 26.201-2014.

152 Alessandri (nota 141), p. 545; Gatica (nota 141), pp. 149-151; Tapia (nota 141), pp. 149-151. 
sino que está limitada a los daños directos previsibles conforme al estándar de cuidado exigible en las circunstancias. Luego, la lógica que subyace al art. 1558 del Código Civil no es ajena a la responsabilidad aquiliana. Por otro lado, porque esta doctrina jurisprudencial sugiere, o al menos suscita la duda, de si la responsabilidad derivada de un delito (o de un cuasidelito civil perpetrado con culpa lata) debería englobar todos los daños directos, incluso los que ni el más escrupuloso modelo de conducta habría podido prever al tiempo del ilícito.

2.4. La responsabilidad aquiliana del que daña deliberadamente o con suma imprudencia debería englobar todos los perjuicios causalmente conectados a tal conducta. Su responsabilidad no debería circunscribirse a los daños previsibles a la época de la perpetración del hecho, pues el dolo excede toda previsibilidad. Esta noción es consustancial a la culpa y a la causalidad adecuada, criterio que hace referencia a lo que un sujeto prudente normalmente habría podido prever. Pero de quien actúa dolosamente, o con absoluta indiferencia, cabe esperar que se representó o debió representarse todas las secuelas nocivas de su comportamiento, por remotas que sean ${ }^{153}$. Asimismo, ceteris paribus, es más probable que un daño se produzca cuando ha sido intentado que cuando únicamente ha sido previsto ${ }^{154}$ : es más probable que una conducta más culpable sea identificada como la causa de un resultado que una menos culpable ${ }^{155}$.

2.5. Para que la jurisprudencia admita el impacto causal del delito civil no se requiere reformar los arts. 2314 y ss. del Código Civil. Desde luego, los tribunales reconocen no solo que el dolo puede influir en el aumento del monto indemnizado por el daño moral sino que, en ciertas áreas que se indican en el número siguiente, aquel es esencial para atribuir el deber de resarcir a la víctima del daño. Enseguida, la ubicación del art. 1558 no es una razón que impida aplicarlo en sede extracontractual, atendiendo en este caso a la época en que se cometió el ilícito ${ }^{156}$. El dolo es uno y el mismo en todo el Código de Bello -la intención positiva de dañar-, ya se exteriorice como vicio del consentimiento, incumplimiento contractual o con independencia de un nexo jurídico previo (art. 2314). El dolo es el delito civil por excelencia ${ }^{157}$. Este es el genuino sentido, criterio cardinal de interpretación de la ley consagrado en el art. 23 del Código Civil ${ }^{158}$, en que debe entenderse el tratamiento del dolo en este cuerpo legal. Por tanto, donde

153 Reglero (nota 12), p. 304.

${ }^{154}$ Kenny, A., "Intention and purpose", en Journal of Philosophy, 1966, N 63, p. 650; Wright, R., "Causation in tort law", en California Law Review, 1985, vol. 73, p. 1770.

155 Cane, P., "Responsibility and fault: a relational and functional approach to responsibility", en Cane, P. \& Gardner, J. (eds.), Relating to responsibility, Oxford, Hart, 2001, p. 107.

156 Para cierta doctrina española el autor del delito debe responder de todos los daños directos aun cuando la agravación está situada en materia contractual (art. 1107 del Código Civil español): De Cossío y Corral (nota 149), pp. 145-146; De Ángel, R., La responsabilidad civil, Bilbao, Universidad de Deusto, 1988, pp. 264-265; Yzquierdo, M., Sistema de responsabilidad civil, contractual y extracontractual, Madrid, Editorial Dykinson, 2001, pp. 248-250.

${ }^{157}$ Chadwick, T., "De la naturaleza jurídica del dolo civil”, en RDJ, T. 36, I, 1939, pp. 1, 8-20 y 63.

158 Guzmán, A. Las reglas del "Código Civil" de Chile sobre interpretación de las leyes. Santiago, Editorial Lexis Nexis, 2007, p. 109-110. 
quiera que se manifieste, el dolo debe producir idénticos efectos indemnizatorios. Estos solo están regulados en los arts. 1458 , inc. $2^{\circ}$, y 1558: el autor del dolo debe reparar todos los daños emanados directamente de su hecho. Esta consecuencia no tiene por qué cambiar en el caso de la responsabilidad aquiliana. En efecto, el art. 2329 ordena reparar todo daño que pueda imputarse (por estar causalmente conectado) a malicia; y, aunque esta norma se refiere también a la negligencia, la jurisprudencia ha declarado que la responsabilidad por culpa solo abarca los daños directos previsibles al tiempo de perpetrarse el cuasidelito. Si bien no se ha fallado qué ocurre con el delito civil, los argumentos expuestos permiten concluir que la responsabilidad aquiliana por dolo debería abarcar todos los perjuicios que derivan directamente de aquel, por imprevisibles o remotos que sean ${ }^{159}$.

\section{El dolo, o la culpa lata, es requisito de la responsabilidad civil en ciertos casos}

3.1. En fin, la jurisprudencia chilena reconoce que el dolo, en cuanto expresión del abuso del derecho, es imprescindible para atribuir responsabilidad civil por los daños que emanan de los actos de competencia desleal ${ }^{160}$ y del ejercicio de acciones judiciales $^{161}$. Ocasionalmente, también, ha exigido un ejercicio abusivo, limítrofe con el dolo, para imputar responsabilidad por los daños generados por la actividad periodística ${ }^{162}$.

3.2. De esta manera, el simple descuido no es suficiente para hacer responder en situaciones en que el perjuicio es un efecto colateral del ejercicio de libertades tan fundamentales como las de competir, de accionar en un proceso y de expresarse e informar. La tensión que existe entre el derecho de la víctima a ser compensada y la libertad de actuación del agente causante del daño solo debe resolverse en favor de la primera si el daño sufrido por ella emana de un delito civil, pues este es el hecho indiciario del ejercicio abusivo o excesivo de la libertad que ostenta el segundo ${ }^{163}$.

\section{Conclusiones}

1. La explicación formal u oficial en los sistemas francés y chileno es coincidente, a saber: la supuesta intrascendencia del dolo en la responsabilidad aquiliana debido al principio de la reparación integral, unido a la inexistencia en este ámbito de una regla

159 "El autor del delito...se obliga, muy a su pesar y por el solo efecto de la ley, a reparar las consecuencias de su acto: su voluntad es indiferente. Importa poco que se hayan previsto o no los daños causados a la víctima”. Chadwick (nota 157), p. 91.

$1602^{\circ}$ JC Santiago, 30.1.2009, rol 12.216-2007, CA Santiago, 22.1.2010, rol 1.414-2009 y CS, 12.11.2010, rol 3.655-2010; $20^{\circ}$ JC Santiago, 27.1.2008, rol 11.535-2008, CA Santiago, 13.1.2010, rol 868-2009 y CS, 17.8.2012, rol 2.428-2010; $8^{\circ}$ JC Santiago, 12.7.2012, rol 15.139-2011, CA Santiago, 1.4.2014, rol 6.335-2012 y CS, 31.7.2014, rol 11.531-2014.

${ }^{161}$ CS, 30.11.2005, rol 4.762-2005; CS, 15.1.2013, rol 9.336-2010; CS, 23.7.2013, rol 8.243-2012.

162 CA Santiago, 30.11.2009, rol 8.214-2008; $2^{\circ}$ JC Santiago, 28.1.2011, rol 28.073-20.071.

163 Banfi (nota 149), passim. 
-como la que se consagra en la responsabilidad contractual- que distinga al dolo de la culpa.

2. Sin embargo, la regla operativa o el derecho vivo en ambos países ${ }^{164}$, plasmado por la práctica jurisprudencial, obliga a matizar la aseveración precedente en dos sentidos: el dolo es un elemento que adquiere trascendencia para incrementar la indemnización, de guisa que con cierta regularidad la responsabilidad civil es utilizada en Francia y en Chile como un instrumento no solo resarcitorio sino también disuasivo o punitivo, e interesantemente esto acontece respecto del daño moral y del daño patrimonial, como es manifiesto en los actos de competencia desleal, y, el dolo -o al menos la culpa grave-, devienen en un presupuesto imprescindible para imputar la responsabilidad civil en sectores acotados de las actividades humanas, cuyo simple ejercicio puede dañar a terceros. En estas áreas se aprecia una permanente tensión entre una libertad fuerte del titular -de competir, de accionar en juicio o de informar-y el derecho de la víctima a ser resarcida. En estas situaciones es razonable limitar la responsabilidad civil a comportamientos intencionales o que revelan una indiferencia extrema hacia los demás, que denotan un abuso del derecho.

3. La responsabilidad civil debería comprender todos los perjuicios directamente causados por el delito (o cuasidelito realizado con culpa lata), incluso los que un sujeto esmerado prudente no habría podido prever al ejecutar el hecho. La jurisprudencia estudiada no ha reconocido esta consecuencia pero ha limitado la responsabilidad por el cuasidelito civil cometido con mero descuido a los daños directos que el buen padre de familia habría sido capaz de prever al tiempo de su comisión. Es decir, en el caso de más ordinaria ocurrencia el principio de reparación integral está circunscrito a los daños previsibles conforme con el estándar de diligencia aplicable.

4. Aún está por verse si la jurisprudencia reconocerá que el autor de un delito, o de un cuasidelito perpetrado con suma imprudencia, debería responder de todos los daños que se sigan de su conducta, por imprevisibles que sean, como aquí se ha argumentado. Primero, la práctica jurisprudencial da cuenta que, en los hechos, la responsabilidad aquiliana cumple una función punitiva limitada: el dolo es un factor que puede incidir en una mayor compensación del daño moral y es un requisito para imputar la responsabilidad por los daños derivados del ejercicio de ciertas libertades. Segundo, el sentido genuino de las reglas pertinentes del Código Civil (arts. 1458 inc. $2^{\circ}, 1558$ y 2329) es que el dolo siempre da lugar a una indemnización comprensiva de todos los daños directos, tanto previsibles como imprevisibles para las partes al tiempo de celebrar el contrato o para el autor a la época de realizar el ilícito extracontractual. Tercero, la jurisprudencia ha declarado, correctamente, que el principio de reparación integral consagrado en el art. 2329 no significa que el autor del cuasidelito deba hacerse cargo de todos los perjuicios que fluyen directamente de su conducta negligente sino únicamente de aquellos daños que habrían podido ser previstos por el modelo de comportamiento aplicable en

${ }^{164}$ Sacco, R., "Legal formants: a dynamic approach to comparative law", American Journal of Comparative Law, 1991, vol. 39, pp. 1-34. 
la especie. Nada ha dicho respecto del dolo, pero parece razonable sostener que el autor de este no debe ser beneficiado mediante el criterio de la previsibilidad: quien actúa intencionalmente se sitúa más allá de toda previsibilidad.

\section{BIBLIOGRAFÍA}

Alessandri, A., De la responsabilidad extracontractual en el derecho civil chileno, Santiago, Imprenta Universitaria, 1943.

Auguet, Y., Droit de la concurrence, Paris, Ellipses, 2002.

BALlot-LÉnA, A., La responsabilité civile en droit des affaires, Paris, LGDL, 2008.

BANFI, C., Responsabilidad civil por competencia desleal. Estudio de derecho chileno y comparado, Santiago, Editorial Thomson Reuters-Legal Publishing, 2013; "Por una reparación integral del daño extracontractual limitada a los hechos dolosos o gravemente negligentes", Revista Ius et Praxis, 2012, Año 18, No 2, pp. 3-32.

Barros, E., Tratado de responsabilidad extracontractual, Santiago, Editorial Jurídica de Chile, 2006.

Bigot de Préameneu, F.J.J., "Présentation au corps législatif et exposé de motifs", en Fenet, P-A., Recueil complet des travaux préparatories du Code civil, Paris, 1827.

Cadiet, L. y Le Tourneau, P., “Abus de droit”, en Savaux, É. (ed.), Dalloz répertoire de droit civil, Paris, Dalloz, 2008, T. I, pp. 1-38.

CAne, P., "Responsibility and fault: a relational and functional approach to responsibility", en Cane, P. \& Gardner, J. (eds.), Relating to responsibility, Oxford, Hart, 2001.

Carbonnier, J., Droit civil. Les obligations, Paris, PUF, 2000, $22^{\mathrm{e}}$ éd.

Carval, S., La responsabilité civile dans sa fonction de peine privée, Paris, LGDJ, 1995.

CoËFfard, P., Garantie des vices cachés et responsabilité contractuelle de droit commun, Paris, LGDJ, 2005.

Conte, P., "Responsabilité du fait personnel”, en Savaux, É. (ed.), Dalloz répertoire de droit civil, Paris, Dalloz, 2009, T. X, pp. 1-55.

Chadwick, T., "De la naturaleza jurídica del dolo civil", RDJ, T. 36, I, 1939, pp. 5-105

Chagny, M., "La notion de dommages et intérêts punitifs et ses répercussions sur le droit de la concurrence", en Lectures plurielles de l'article 1371 de l'avant-projet de réforme du droit des obligations, JCP, 2006, I, No 149; Droit de la concurrence et droit commun des obligations, Paris, Dalloz, 2004.

De Ángel, R., La responsabilidad civil, Bilbao, Universidad de Deusto, 1988.

De Cossío y Corral, A., El dolo en el derecho civil, Madrid, Editorial Revista de Derecho Privado, 1955.

De van Karila, J., "The droit to nuire”, RTD. Civ., 1995, pp. 533-558.

Demolombe, C., Traité des contrats ou des obligations conventionelles en général. Cours de Code Napoléon, Paris, Durand-Hachette, 1868.

DíEz, J., El daño extracontractual. Jurisprudencia y doctrina, Santiago, Editorial Jurídica de Chile, 1997.

Domínguez, C., "El principio de reparación integral del daño y su contenido: algunas consecuencias para el derecho chileno", en Departamento de Derecho Privado Universidad de Concepción (coord.), Estudios de Derecho Civil V, Santiago, Editorial Abeledo Perrot - Legal Publishing, 2010, pp. 671-685.

Domínguez, R., "Los límites al principio de reparación integral", Revista Chilena de Derecho Privado, 2010, $\mathrm{N}^{\circ} 15$, pp. 9-28; "Consideraciones en torno a la noción de daño en la responsabilidad civil. Una visión comparatista”, Revista de Derecho Universidad de Concepción, 1990, No 188 , pp. 125-168. 
DREYeR, E., "La perversion du référé en matière de prense", JCP, 2007, I, Nº 171.

Esmein, P., "Le fondement de la responsabilité contractuelle", RTD. Civ, 1933, pp. 627 y ss.

FASQuelle, D., "La réparation des dommages causés par les pratiques anticoncurrentielles", RTD. Com., pp. 763-794.

Galand-Carval, S., "Fault under French law", en Widmer, P. (ed.), Unification of tort law: fault, European Centre of Tort and Insurance Law, The Hague, Kluwer, 2005, vol. 10, pp. 89-100.

Gatica, S., Aspectos de la indemnización de perjuicios por incumplimiento del contrato, Santiago, Editorial Jurídica de Chile, 1959.

GORDley, J., Foundations of private law, Oxford, OUP, 2006.

Graëve, L., Essai sur le concept de droit de punir en droit interne, Lyon III, thèse, 2006.

Granier, J., "Quelques réflexions sur l'action civile", JCP, 1957, I, Nº 1386.

Grare, C., Recherches sur la cóherence de la responsabilité délictuelle. L'influence des fondements de la responsabilité sur la réparation, Paris, Dalloz, 2005, $\mathrm{N}^{\circ} 482$.

Izorche, M., "Les fondaments de la sanction de la concurrence déloyale et du parasitisme", RTD. Com., 1998, pp. 17-52.

Jambu-Merlin, R., "Dol et faute lourde”, D., Paris, 1955, Chronique, p. 89

JAULT, A., La notion de peine privée, Paris, LGDJ, 2005.

Kenny, A., "Intention and purpose", en Journal of Philosophy, 1966, N 63, pp. 642-651.

LAMBERT-Faivre, Y., "L'évolution de la responsabilité civile: d'une dette de responsabilité à une créance d'indemnisation", RTD. Civ., 1987, pp. 1 y ss.

Lapoyade-Deschamps, C., "La réparation du préjudice économique pur en droit français, Revue International de Droit Comparé, 1998, pp. 379 y ss.

Larraín, C., "Aproximación a los punitive damages", en Pizarro, C. (coord.), Estudios de Derecho Civil IV, Santiago, Editorial Legal Publishing, 2009, pp. 707-719.

LAsserre-Kiesow, V., "La promotion des sanctions civiles en droit des pratiques anticoncurrentielles”, D., 2007, Chronique, pp. 2116-2119.

Leturmy, L., "La responsabilité délictuelle du contractant", RTD. Civ., 1998, pp. 839 y ss.

Le Tourneau, P., "Responsabilité (en général)”, en Savaux, É. (éd.), Dalloz répertoire de droit civil, Paris, Dalloz, 2009, T. X, pp. 1-68; "La verdeur de la faute dans la responsabilité civile (ou de la relativité de son déclin)", RTD. Civ., 1998, pp. 505-518.

Lefebvre, D., "La spécificité du droit commercial. Réflexion sur la place tenue, en droit privé, par le droit commercial par rapport au droit civil", RTD. Com., 1975, pp. 285 y ss.

Malaurie-Vignal, M., Droit de la concurrence interne et communautaire, Paris, Sirey, 2008, $4^{\mathrm{e}}$ éd.

MARTy, G., "La relation de cause à effet comme condition de la responsabilité civile", RTD. Civ., 1939, pp. 685 y ss.

Mazeaud, H., "La 'faute objective' et la responsabilité san faute", D., 1985, Chronique, p. 13

Mazeaud, H. y Mazeaud, L., Traité théorique et pratique de la responsabilité civile délictuelle et contractuelle, Paris, Sirey, 1949, $4^{\mathrm{e}}$ éd.

Mazeaud, H., Mazeaud, L., Mazeaud, J. y Chabas, F., Legons de droit civil., Paris, Montchrestien, $1998,9^{e}$ éd.

Nguyen, D., "Contribution a l'étude de la faute contractuelle: le faute dolosive et sa place actuelle dans la gamme des fautes", RTD. Civ., 1973, pp. 496-521.

Pollaud-Dulian, F., "De quelques avatars de l'action en responsabilité civile dans le droit des affaires", RTD. Com., 1997, pp. 348-381.

Quézel-Ambrunaz, C., Essai sur la causalité en droit de la responsabilité civile, Paris, Dalloz, 2010.

RADÉ, D., "L'impossible divorce de la faute et de la responsabilité civile", D., Paris, 1998, Chronique, pp. 301-305.

Reglero, F., Tratado de responsabilidad civil, Navarra, Thomson Reuters, 2014, $5^{\mathrm{a}} \mathrm{ed}$. 
RIPERT, G., Le règle morale dans las obligations civiles, Paris, LGDJ, 1949, $4^{\mathrm{e}} \mathrm{ed}$.

Roujou de Boubée, M-E., Essai sur la notion de réparation, Paris, LGDJ, 1974.

Rousseau, M., "La dificulté d'établir la responsabilité civile de l'entreprise en matière d'environnement", JCP, supplément aux Cahiers du droit de l'entreprise, 1999, $\mathrm{N}^{\circ} 1$, pp. 19 y ss.

SACCO, R., "Legal formants: a dynamic approach to comparative law", American Journal of Comparative Law, 1991, vol. 39, pp. 1-34 y 343-401.

Savatier, R., Traité de la responsabilité civile en droit français, Paris, LGDJ, 1951.

Serra, Y., "Concurrence déloyale”, en Vogel, L. (éd.), Dalloz répertoire de droit commercial. Dalloz encyclopédie juridique, Paris, Dalloz, 2004, pp. 1-47; "La validité de la clause de non-concurrence", D., 1987, Chronique, pp. 113-116.

Schaeffer, E., "L'abus dans le droit de la concurrence", Gaz. Pal, 1981, 2, doctrine, pp. 401-408.

Souleau, I., La prévisibilité du dommage contractuel, défense et illustration de l'article 1150 du Code Civil, Paris, Université de Droit, d'Économie et Sciences Sociales, 1979, thèse

STARCK, B., "Domaine et fondement de la responsabilité sans faute", RTD. Civ., 1958, pp. 475515; Essai d'une théorie générale de la responsabilité civile consideré en sa double fonction de garantie et de peine privée, Paris, Rodstein, 1947.

Starck, B., Roland, H. y Boyer, L., Obligations. Responsabilité délictuelle, Paris, LITEC, 1996, $5^{\text {e éd. }}$

TAPIA, O., De la responsabilidad civil en general y de la responsabilidad delictual entre los contratantes, Santiago, Editorial LexisNexis, 2007, $3^{\text {a }}$ ed.

Tunc, A., La responsabilité civile, Paris, Economica, 1989, $2^{\mathrm{e}}$ éd.

Vignon-Barrault, A., Intention et responsabilité civile, Marseille, PUAM, 2004.

VINEY, G., Traité de droit civil. Introduction à la responsabilité, Paris, LGDJ, 1995, 2 éd.; Le déclin de la responsabilité individuelle, Paris, LGDJ, 1965.

VINey, G. y Jourdain, P., Traité de droit civil. Les conditions de la responsabilité, Paris, LGDJ, 2006, $4^{\mathrm{e}}$ éd.; Traité de droit civil. Les effets de la responsabilité, Paris, LGDJ, 2001, $2^{\mathrm{e}}$ éd.

Wagner, G., "Comparative tort law", en Reimann, M. \& Zimmermann, R. (eds.), The Oxford handbook of comparative law, Oxford, OUP, 2006, pp. 1003-1041.

Wright, R., "Causation in tort law", California Law Review, 1985, vol. 73, pp. 1737-1828.

YzQuierdo, M., Sistema de responsabilidad civil, contractual y extracontractual, Madrid, Editorial Dykinson, 2001.

\section{Sentencias francesas}

CAss. Req.: 9.11.1871, DP, 1871, 1, p. 211.

CIv.: 21.7.1890, DP , 1891, 1, p. 380; 14.3.1892, DP, 1892, 1, p. 523; 24.5.1913, DP 1916, 1, p. $171 ; 28.7 .1965$, D. 1965 , p. 777 , n. Esmein; 8.10.1975, D., 1975, IR, p. 258.

CIv. (1): 5.2.1957, D., 1957, p. 232; 7.10.1965, Bull. civ., I, No 519; 4.2.1969, D., 1969, p. 601, n. Mazeaud; 9.4.1975, RTD. Civ., 1976, p. 781, obs. Durry; 20.7.1976, JCP, 1978, II, p. 18.793, n. Dejean de la Bâtie; 11.5.1982, Gaz. Pal, 1982, 2, p. 612, n. Chabas; 1.3.1983, Gaz. Pal, 1984, 1, panor., p. 58, obs. Chabas; 11.7.1988, Bull. civ., I, No 237; 26.2.1991, Bull. civ., I, No 73; 13.12.1994, Bull. civ., I, 372; 19.11.1996, Bull. civ. I, No 404, p. 283; 17.12.1996, Bull. civ., I, No 458; 30.11.2004, Bull. civ., I, No 295; 5.4.2005, RTD. Civ., 2005, p. 607, obs. Jourdain; 22.11.2007, Bull. civ., No 06-14174.

CIv. (2): 11.12.1952, D., 1953, p. 317, n. Savatier; 28.10.1954, Bull. civ., II, No 328, RTD. Civ., 1955, p. 324, obs. Mazeaud; 21.11.1956, D., 1957, p. 52; 18.12.1963, Bull. civ., 1963, II, $\mathrm{N}^{\circ}$ 635; 4.5.1964, JCP, 1965, $\mathrm{N}^{\circ}$ 14.140, n. Esmein; 18.11.1966, Bull. civ., II, $\mathrm{N}^{\circ}$ 906; 16.7.1969, Bull. civ., II, No 256; 11.1.1973, Gaz. Pal, 1973, II, p. 710; 21.4.1982, Gaz. 
Pal, 1983, 2, p. 591, n. Chabas; 15.6.1988, Bull. civ., II, No 146; 19.10.1988, Bull. civ., II, $\mathrm{N}^{\circ} 200 ; 13.2 .1991$, Bull. civ., II, $\mathrm{N}^{\circ} 51 ; 22.1 .2009$, $\mathrm{N}^{\text {os }}$ 07-20.878 y 08-10.392, D., 2009, p. 1114, n. Loir.

CIv. (3): 22.2.1968, Bull. civ., III, No 71, D., 1968, p. 607, note Ph. M.; 23.5.1968, D., 1970, p. 463, n. Jestaz; 4.2.1971, JCP, 1971, II, p. 16.781, n. Lindon; 12.10.1971, D., 1972, p. 210; 18.12.1972, D., 1973, p. 272, n. Mazeaud; 2.7.1975, Bull. civ. III, No 233; 25.6.1986, JCP, 1986, IV, p. 262; 23.1.1991, Bull. civ., III, No 28; 27.6.2001, Bull. civ., III, No 83, RTD. Civ., 2001, p. 887, obs. Jourdain.

Coм.: 18.4.1958, D., 1959, p. 87, n. Derrida; 25.3.1963, D., 1964, p. 17, n. Rodière; 11.5.1976, D., p. 76, Somm. 64; 16.2.1977, Bull. civ., IV, No 51; 6.3.1978, JCP, 1978, II, p. 19.001, n. Azéma; 17.1.1979, Bull. civ., IV, No 42; 3.5.1979, Bull. civ., IV, No 137, p. 138; 1.3.1982, Bull. civ., $\mathrm{N}^{\circ} 76$; 4.2.1984, D., 1985, somm. 86; 22.10.1985, D., 1986, IR, p. 339, obs. Serra; 6.5.1986, D., 1986, IR, p. 339, n. Serra; 25.11.1986, Bull. civ., IV, No 218; 18.12.1986, D., 1987, IR, p. 19; 21.6.1988, Bull. civ., IV, No 210; 2.11.1993, RTD. Civ., 1994, p. 622, obs. Jourdain, JCP, 1995, I, 3853, p. 25, obs. Viney; 5.7.1994, JCP, 1995, I, 3, p. 3828 , obs. Fabre-Magnan; 30.1.1996, D., 1997, p. 232, obs. Serra; 27.2.1996, D., 1997, somm., p. 104, obs. Serra; 7.4.1998, D., 1999, somm., p. 128, obs. Schmidt-Szalewski; 20.10.1998, Revue de jurisprudence de droit des affaires, 1999, $\mathrm{N}^{\circ}$ 109; 3.5.2000, D., 2001, somm., p. 1312, obs. Serra; 24.10.2000, Bulletin rapide de droit des affaires, 2000, No 21, p. 12, obs. Serra; 30.1.2001, D., 2001, p. 1939, n. Le Tourneau; 3.4.2001, Bull. civ., IV, No 70; 17.7.2001, No 99-17.189; 9.10.2001, RTD. Civ., 2002, p. 304, obs. Jourdain; 9.7.2002, No 99-19.156, RTD. Com., 2003, p. 363, obs. Bouloc; Com. 22.10.2002, Sté Vidal, Contrats, conc., consom. $2003 \mathrm{~N}^{\circ}$ 2.; 2003/707, 21.5.2003; 30.6.2004, Bull. civ., IV, No 144; 21.2.2006, D., 2006, AJ, p. 717, obs. Chevrier.

CA Paris: 10.7.1986,JCP, 1986, II, p. 20.712, n. Agostini; 5.3.1987, D., 1988, somm. 180, obs. Serra; 6.11.1989, D., 1990, p. 564, n. Thouvenin; 27.5.1992, D., 1993, somm. 155, obs. Izorche; 20.3.1995, Gaz. Pal, 1995, 2, somm. p. 473; 24.3.1995, D., 1996, somm., p. 252, obs. Izorche; 3.7.1996, RJDA, 1996, No 1422; 9.6.1999, D., 2000, somm. 325, obs. Auguet.

CA Versailles: 19.1.1995, D., 1995, p. 259, obs. Serra.

CRIM.: 10.7.1952, JCP, 1952, II, p. 7272, n. Cornu.

Conseil constitutionnel: Décis. No 04-D-10, 1.4.2004, UGC; 22.7.2005, No 2005-522, JCP, 2006, I. 111, obs. Stoffel-Munck.

\section{Sentencias chilenas}

CS: $12.8 .1953, R D J$, T. 50, sec. $1^{\text {a }}$, p. 288; 26.11.1970, RDJ, T. 67 , sec. $1^{\text {a }}$, p. 535; 17.10.1972, $R D J$, T. 69 , sec. $4^{\mathrm{a}}$, p. $168 ; 12.8 .1981, R D J$, T. 78 , sec. $4^{\mathrm{a}}$, p. 120; 14.9.1987, RDJ, T. 84, sec. $4^{\text {a }}$, p. $137 ; 2.12 .1998, F M, \mathrm{~N}^{\circ} 481$, p. $2.737 ; 24.1 .2002, G J, \mathrm{~N}^{\circ} 259$, p. 38; 24.3.2004, GJ, $\mathrm{N}^{\circ} 285$, p. 138; 30.11.2005, rol 4.762-2005; 15.1.2013, rol 9.336-2010; 23.7.2013, rol 8.243-2012; 9.12.2013, rol 314-2010; 12.6.2015, rol 26.201-2014; 3.12.2015, rol 29.365-2014.

CA Santiago: 30.11.2009, rol 8.214-2008.

$2^{\circ}$ JC Santiago: 28.1.2011, rol 28.073-2007; 30.1.2009, rol 12.216-2007 (CA Santiago, 22.1.2010, rol 1.414-2009, y; CS, 12.11.2010, rol 3.655-2010).

$8^{\circ}$ JC Santiago: 12.7.2012, rol 15.139-2011 (confirmado CA Santiago, 1.4.2014, rol 6.335-2012, y; CS, 31.7.2014, rol 11.531-2014).

$20^{\circ}$ JC Santiago: 27.1.2008, rol 11.535-2008 (confirmado CA Santiago, 13.1.2010, rol 8682009, y; CS, 17.8.2012, rol 2.428-2010). 
